\title{
Safe Motherhood Applied Research and Training (SMART) Report 4: Knowledge and behaviour of service providers
}

Zakir Hussain Shah

Saima Pervaiz

Follow this and additional works at: https://knowledgecommons.popcouncil.org/departments_sbsr-rh

Part of the Demography, Population, and Ecology Commons, Family, Life Course, and Society Commons, Gender and Sexuality Commons, International Public Health Commons, Maternal and Child Health Commons, and the Medicine and Health Commons How does access to this work benefit you? Let us know!

\section{Recommended Citation}

Shah, Zakir Hussain and Saima Pervaiz. 2006. "Safe Motherhood Applied Research and Training (SMART) Report 4: Knowledge and behaviour of service providers." Islamabad: Population Council. 


\section{Safe Motherhood Applied Research \& Training SMART}

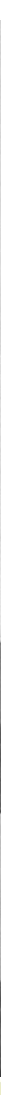

\section{Knowledge and Behavior of Service Providers}





\section{Safe Motherhood Applied Research \& Training Project SMART}

\section{SMART Report 4 Knowledge and Behaviour of Service Providers}

Zakir Hussain Shah Saima Pervaiz 


\section{(2) Population Council}

The Population Council, an international, non profit, nongovernmental organization established in 1952, seeks to improve the well being and reproductive health of current and future generations around the world and to help achieve a humane, equitable, and sustainable balance between people and resources.

The Council analyses population issues and trends; conducts research in the reproductive sciences; develops new contraceptives; works with public and private agencies to improve the quality and outreach of family planning and reproductive health services; helps governments design and implement effective population policies; communicates the results of research in the population field to diverse audiences; and helps strengthen professional resources in developing countries through collaborative research and programmes, technical exchanges, awards, and fellowships.

\section{For inquiries, please contact:}

\section{Population Council}

House \#7, Street 62, F-6/3, Islamabad, Pakistan

Tel: 92512277439

Fax: 92512821401

Email: info@pcpak.org

Web: http://www.popcouncil.org

Layout \& Design: Ali Ammad

Printed by: Crystal Printers

Published: October 2006

The Population Council reserves all rights of ownership of this document. No part of this publication may be reproduced, stored or transmitted in any form by any means electronic, photocopying, recording or otherwise without the permission of the Population Council. 


\section{Safe Motherhood Applied Research and Training Project (SMART)}

The Safe Motherhood Applied Research and Training (SMART) project, an operations research project designed to develop and test interventions to reduce maternal, perinatal and neonatal mortality and morbidity in predominantly rural districts of Pakistan, was a three-year project funded by the European Union. Project implementation ran from October 2003 to October 2006. The study area was in the district of Dera Ghazi Khan; the control area was in the district of Layyah.

The project focused on three areas as a means of accomplishing its goals: empowering women to seek appropriate and timely general, maternal and newborn care; supporting methods that encourage men to play a positive and active role in decision-making and seeking care for their families in matters relating to maternal and newborn care; and improving and strengthening health services.

The project had two intervention sites and one control site in order to look at the impact of two different interventions (within communities and within health facilities). It was expected that project results would be useful to others working toward reducing maternal, perinatal and neonatal mortality and morbidity, nationally and internationally.

The interventions and findings from this study have been published in six reports, which are available from the Population Council.

SMART Report 1: Project Overview

SMART Report 2: The Interventions

SMART Report 3: Change in Knowledge and Behaviour of Women and Families

SMART Report 4: Knowledge and Behaviour of Service Providers

SMART Report 5: Verbal Autopsies of Infant and Maternal Death

SMART Report 6: Formative Research on Maternal and Neonatal Health 


\section{Acknowledgements}

The Population Council would like to thank the European Union for its generous funding and support for this project.

We would also like to thank the Departments of Health of Dera Ghazi Khan and Layyah Districts for their willingness to allow these surveys to take place within their jurisdictions.

This report was drafted by Dr Zakir Hussain Shah, Deputy Programme Manager, who wrote the first draft of this report, and worked closely with Dr Zeba A. Sathar, Country Director, to produce the final product.

Dr Zeba A. Sathar, Country Director, Population Council provided overall guidance for the successful completion of the project, and in particular provided valuable advice throughout for the implementation of the research components of the SMART project.

Mr Peter Miller, Deputy Country Director, Population Council provided direction and insight during the analysis and drafting of this report. Special thanks are due for Dr. Fariyal Fikree who was the external reviewer of this report and gave valuable suggestions and inputs. We are also grateful to Dr. Sabiha Askari who did the language editing of the final product.

Ms Saima Pervaiz, Staff Officer, supervised the fieldwork in both rounds of these surveys and has contributed in the analysis and write-up.

We are thankful to Dr. Gul Rasheeda for her support, inputs and cooperation as a Project Director. Dr Farid Midhet conceptualized this project, designed the research strategy, and developed the overall protocols. Irfan Masood, Wajahat Raza, Zia Ul Islam, Rehan Niazi, and Jibran were involved in data entry and generating tables and graphs for the report. Dr Mazhr Jaskani, Dr Farhaj Shumail and Dr Uzma led the field data collection. Minhaj ul Haq and Dr Arshad Mehmood provided valuable inputs during the completion of this report.

We thank and appreciate Ali Ammad, who designed the layout and did a splendid work to format this report. 


\section{Contents}

I. Introduction ...................................................................................... 1

Background ..................................................................... 1

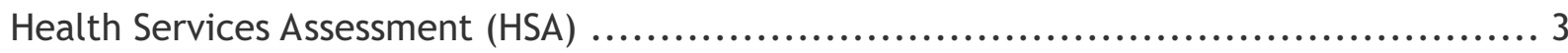

Research Tools ................................................................... 4

Data Collection Phase ................................................................ 5

Status of Facilities and data .......................................................... 7

II. Knowledge of Service Providers: Maternal, Neonatal, and Infant Care ................... 9

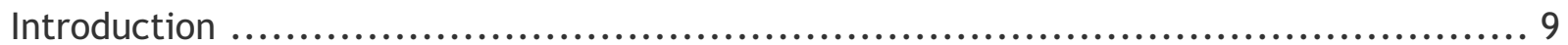

Results .............................................................................. 11

III. Readiness of the District Health Delivery System for Maternal and Neonatal Care...... 17

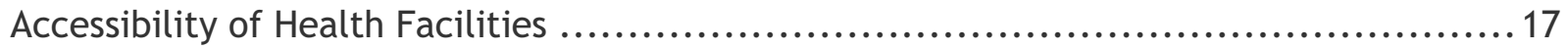

Basic Infrastructure of Fixed Clinics .................................................... 18

Medical Examination Facilities ...................................................... 19

Medicines, their Storage and Record Facilities ......................................... 21

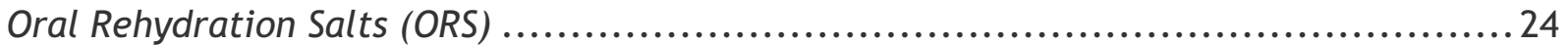

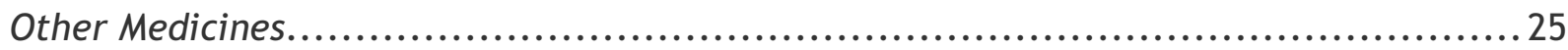

Other Material/Supplies............................................................. 26

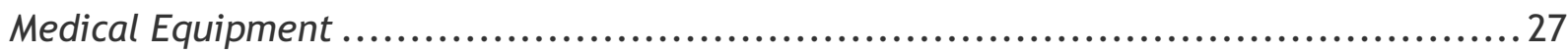

General Use Equipment............................................................... 30

Services Available at Fixed Clinics ....................................................... 32

IV. Behaviour of Service Providers ...........................................................39

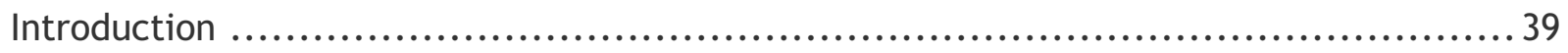

Characteristics of Service Providers .................................................. 41

Results ........................................................................... 42

Discussion ........................................................................... 47

V. Perceptions of Clients Regarding Service Providers .............................................49

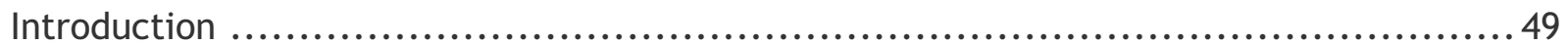

Results ............................................................................. 53

VI. Conclusions and Recommendations............................................................61

Health Delivery System ............................................................ 61

Technical Knowledge of Service Providers ................................................6 62

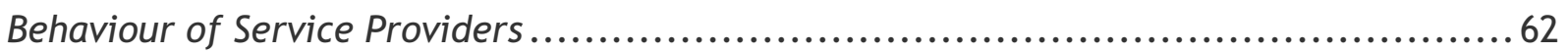

Annexes.........................................................................................................65

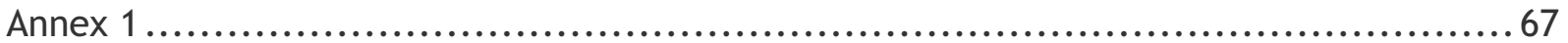





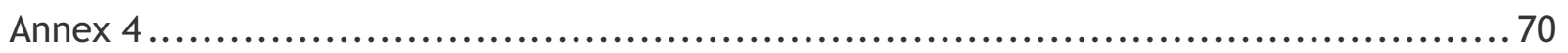




\section{Figures}

Figure 2.1: Knowledge regarding pregnancy........................................ 13

Figure 2.2: Knowledge regarding delivery ........................................... 14

Figure 2.3: Knowledge regarding infant health ..................................... 15

Figure 2.4: Knowledge regarding shock management.................................. 16

Figure 3.1: Percentage of PHCs connected or near a metalled road and that have private female and male doctors available................................... 18

Figure 3.2: Percentage of PHCs with complete team of service providers (baseline) ....... 33

Figure 3.3: Percentage of PHCs with present service providers on the day of visit (baseline) ................................................................... 34

Figure3.4: Percentage of BHUs where different child health services were availableBL vs. EL ................................................................. 34

Figure 3.5: Number of RHC having services related to maternal health, at baseline and endline ............................................................... 35

Figure 3.6: Average number of cases for immunization and ORS therapy at PHCs during one month (Baseline: January 2004. Endline: June 2006) ............... 36

Figure 3.7: Average number of cases for maternal health care at PHC during one month (Baseline: January 2004. Endline: June 2006) ........................ 37

Figure 4.1: Percentage of service providers following norms of salutation ............... 43

Figure 4.2: Percentage of service providers assessing the RH needs and intentions of clients.................................................................... 44

Figure 4.3: Percentage of service providers using communication tools during clientprovider interaction ....................................................... 45

Figure 4.4: Percentage of service providers providing help and guidance to the clients......................................................................... 46

Figure 5.1: Designation of service providers consulted by women during the facilitybased exit ................................................................. 51

Figure 5.2: Designation of service providers consulted by the women during facilitybased exit ................................................................... 52

Figure 5.3: Distribution of respondents by purpose of visit. Facility based exit at BL and EL.................................................................... 52

Figure 5.4: Distribution of respondents by purpose of visit. Community based exit at

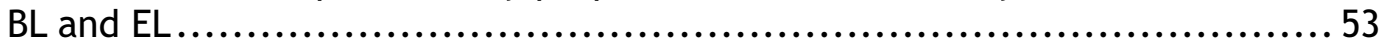

Figure 5.5: Perceptions of clients regarding assessment skills of the service providers (FBE) ............................................................... 54

Figure 5.6: Perceptions of clients regarding assessment skills of the service providers

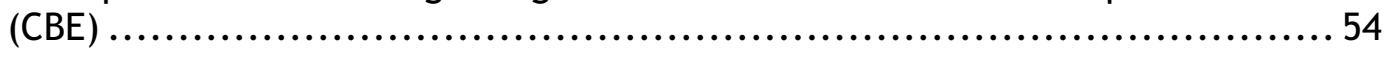




\section{Tables}

Table 1.1: $\quad$ Number of facilities by type included in assessment (both rounds) ............ 7

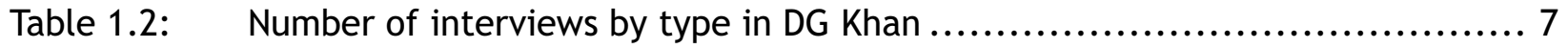

Table 1.3: Tehsil-wise distribution of heal th care facilities visited $\ldots \ldots \ldots \ldots \ldots \ldots \ldots \ldots \ldots . . \ldots$

Table 2.1: Characteristics of respondents: Health Care Provider interviews .............. 10

Table 3.1: $\quad$ Number of health facilities with basic infrastructure in place ................. 18

Table 3.2: $\quad$ Number of health outlets with basic physical facilities in the examination area ....................................................................... 19

Table 3.3: Number of health facilities following the 4 steps of infection prevention ...... 20

Table 3.4: Number of health facilities where necessary arrangements for privacy of the client were maintained ................................................... 21

Table 3.5: Number of health facilities with availability of medicines to treat

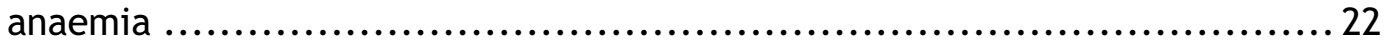

Table 3.6: Number of facilities with availability of necessary maternal health medicines ............................................................. 23

Table 3.7: $\quad$ Number of health facilities with available antibiotics ........................ 23

Table 3.8: Number of health facilities with availability of important intravenous fluids .................................................................. 24

Table 3.9: $\quad$ Number of health facilities where ORS was available ........................... 24

Table 3.10: Number of health facilities with availability of important medicines for general patients..................................................... 25

Table 3.11: Number of health facilities with availability of dressing material .............. 26

Table 3.12: Number of health facilities with adequate storage conditions ................. 27

Table 3.13: Number of facilities with necessary equipment for maternal health care ..... 28

Table 3.14: Number of health facilities with necessary equipment for child health care .................................................................. 28

Table 3.15: Number of health facilities with necessary equipment for emergency care ........................................................................ 29

Table 3.16: Number of health facilities with necessary equipment for general use......... 30

Table 3.17: Number of health facilities with necessary accessories for MCH services ...... 31

Table 3.18: General profile of service providers at visited primary health care

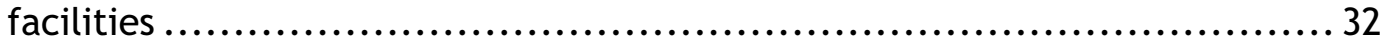

Table 4.1: Total number of observation of service providers in both rounds .............41

Table 4.2: $\quad$ General characteristics of service providers for the observations during both rounds of HSA

Table 5.1: Number of interviews conducted with women at the facility and at home (both rounds) ......................................................... 49

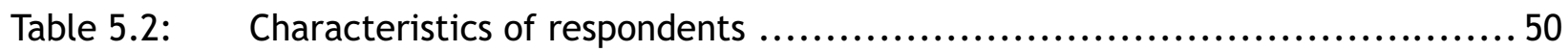


Table 5.3: $\quad$ Perceptions of service providers regarding referral information received by the service provider (facility based exit interviews and community based exit interviews) ................................................... 56

Table 5.4: Perceptions of clients regarding history taking skills of the service provider ................................................................ 57

Table 5.5: $\quad$ Perceptions of clients regarding examination skills of the service provider

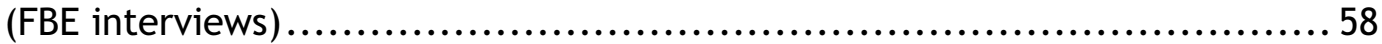

Table 5.6: Perceptions of clients regarding information given by the service provider... 59 


\section{Abbreviations}

\begin{tabular}{|c|c|}
\hline ANC & Antenatal Care \\
\hline ADB & Asian Development Bank \\
\hline $\mathrm{BHU}$ & Basic Health Unit \\
\hline BSMI & Balochistan Safe Motherhood Initiative \\
\hline CBI & Community-Based Intervention \\
\hline $\mathrm{CBO}$ & Community-Based Organization \\
\hline CCA & Client-Centred Approach \\
\hline $\mathrm{CMC}$ & Community Mobilization Component \\
\hline DG KHAN & Dera Ghazi Khan \\
\hline DHDC & District Health Development Centre \\
\hline DHQ & District Headquarter Hospital \\
\hline DHDC & District Health Development Centre \\
\hline EDO & Executive District Officer \\
\hline EmOC & Emergency Obstetric Care \\
\hline EmONC & Emergency Obstetric and Neonatal Care \\
\hline ENMR & Early Neonatal Mortality Rate \\
\hline EOC & Essential Obstetrical Care \\
\hline $\mathrm{EU}$ & European Union \\
\hline FGD & Focus Group Discussion \\
\hline FMT & Female Medical Technician \\
\hline FP & Family Planning \\
\hline F. Sterilization & Female Sterilization \\
\hline FWW & Family Welfare Workers \\
\hline HHS & Household Survey \\
\hline HSA & Health Services Assessment \\
\hline HSI & Health Services Intervention \\
\hline IEEC & Information and Education for Empowerment and Change \\
\hline IEC & Information Education Communication \\
\hline IUCD & Intrauterine Contraceptive Device \\
\hline LHW & Lady Health Worker \\
\hline LHS & Lady Health Supervisor \\
\hline LHV & Lady Health Visitor \\
\hline MCHCenter & Maternal and Child Health Centre \\
\hline MDG & Millennium Development Goals \\
\hline $\mathrm{MNH}$ & Maternal and Neonatal Health \\
\hline
\end{tabular}




\begin{tabular}{|c|c|}
\hline M.Sterilization & Male Sterilization \\
\hline MMR & Maternal Mortality Ratio \\
\hline $\mathrm{MO}$ & Medical Officer \\
\hline MT & Medical Technician \\
\hline MWRA & Married Women of Reproductive Age \\
\hline NRSP & National Rural Support Programme \\
\hline NMR & Neonatal Mortality Rate \\
\hline OTT & Operation Theatre Technician \\
\hline PAIMAN & Pakistan Initiative for Mothers and Newborns \\
\hline PC & Population Council \\
\hline PHC & Primary Health Care \\
\hline PHF & Primary Health Facility (BHU/ RHC) \\
\hline PIMS & Pakistan Institute of Medical Sciences \\
\hline PNMR & Perinatal Mortality Rate \\
\hline PSLMS & Pakistan Social and Living Standard Measurement Survey \\
\hline PWD & Population Welfare Department \\
\hline QoC & Quality of Care \\
\hline RHC & Rural Health Centre \\
\hline RHSC A & Reproductive Health Services Centre A \\
\hline SES & Socioeconomic Status \\
\hline SMART & Safe Motherhood Applied Research and Training \\
\hline SAHR & Salutation Assess Help Reassure \\
\hline SMAM & Singulate Mean Age at Marriage \\
\hline TBA & Traditional Birth Attendant \\
\hline TCL & Training at Community Level \\
\hline TFR & Total Fertility Rate \\
\hline THQ & Tehsil Headquarter Hospital \\
\hline TOT & Training of Trainers \\
\hline UNFPA & United Nations Fund for Population Activities \\
\hline VBFPW & Village-Based Family Planning Worker \\
\hline $\mathrm{VC}$ & Village Committee \\
\hline VHC & Village Health Committee \\
\hline $\mathrm{WMO}$ & Woman Medical Officer \\
\hline
\end{tabular}




\section{Introduction}

\section{Background}

Pakistan is among the countries with a high fertility and high maternal and infant mortality rates. Despite advances in medical technology, maternal mortality remains high in Pakistan: an estimated 30,000 women die each year due to obstetric complications. A disproportionate majority of these deaths occur in rural areas and urban slums. The maternal mortality ratio (MMR) varies between 100 and 700 per 100,000 live births, depending upon socioeconomic status and residence. Antepartum and postpartum haemorrhage, eclampsia, puerperal sepsis, and obstructed labour are the leading causes of maternal deaths. Women having their first birth, those under 18 or over 34 years, and those with a previous history of obstetric complications or poor pregnancy outcomes are at higher risk of maternal mortality.

A vast majority of maternal deaths are attributed to delays in getting medical care during obstetric complications. The first delay is partly due to household constraints, i.e., mainly ignorance on the part of women's families and birth attendants (usually traditional midwives) that delays the decision to seek medical care. The second delay occurs once the decision to seek medical care has been made, when precious time is lost in transporting women to hospitals due to the absence of telephones and regular ambulance services. The third delay occurs at the hospital and is largely due to non availability of trained staff, lack of supplies and equipment, and poorly organized emergency services.

Despite continued efforts and government interest, Pakistan has not succeeded in achieving the International Conference on Population and Development (ICPD-94) milestone. In the near past, there has been a shift in policy orientation toward reproductive health and safe motherhood at the federal and provincial levels. Decentralization of power to the district level has provided a window of opportunity for improving the health system.

Government health services in Pakistan comprise fixed facilities that provide mainly curative care. Essential obstetric care (EOC) is available only in large city hospitals. Very few primary level health facilities provide prenatal care or family planning. Although the government has recently introduced community-based lady health workers, they are not operational or effective in all areas, and their training and job descriptions do not include safe motherhood as a priority area. Although, on paper, they are supposed to work in concert with traditional midwives and to supervise deliveries, they have no formal links with traditional midwives (who conduct almost two-thirds of all deliveries in rural areas) or with health facilities. Finally, there is no 


\section{Introduction}

community-based mechanism for monitoring the performance of government health facilities. Health personnel are not accountable to communities, who, in turn, have little interest or faith in the government health system. The ministries of health and population welfare are working in tandem, with increasing co-operation and integration, but, at times, duplicating efforts. However, the government realizes these shortcomings, and there have recently been efforts to integrate the field operations of these two ministries responsible for women's reproductive health needs. An ambitious national reproductive health services package is being promoted, with input from international and bilateral funding agencies. Implementation will be an uphill task in the absence of pilot operation research projects.

Under these circumstances, there was a need to introduce the concept of community-based interventions in safe motherhood. Such interventions should encourage and facilitate the use of reproductive health services. Interventions will focus on raising community awareness of safe motherhood and on improving accessibility to reproductive health services. Government health services would have to be improved and upgraded to adequately respond to increased demand.

Some innovative approaches have been tested in the recent past to improve the quality of care of the District Health System. One of these is the implementation of "A Client-Centered Approach" for delivering Reproductive Health Services by the Population Council. This project was implemented in one tehsil (Bhalwal) of District Sargodha in central Punjab. In this operations research project, the intervention comprised of training the health care providers from the Health and Population departments to adopt a client-centered approach. It consisted of six days of classroom training all services providers working at static clinics (DHQ, THQ, RHC, BHU, and FWC) and in the community (LHWs and VBFPWs). The main thrust of this interactive training was on behaviour change of service providers towards their clients and on improving their interpersonal skills. The results of this project showed a positive change. The CCA was further scaled up in five other districts of Pakistan under an UNFPA funded project.

Another OR project was implemented by The Asia Foundation, with the financial assistance of $\mathrm{NIH/USA}$ and ADB, in Khuzdar district of Balochistan. This was the Balochistan Safe Motherhood Initiative (BSMI). The core intervention included training of health care providers in Emergency Obstetric Care (Basic and Comprehensive) and community mobilization.

It was in this context that by bridging the experiences of above two initiatives, an operations research project was implemented in District Dera Ghazi Khan titled as Safe motherhood Applied Research and Training (SMART) 


\section{Health Services Assessment (HSA)}

Health Service Assessment (HSA) is a part of the research activities carried out in district DG Khan during 2004 and 2006, under the Safe Motherhood Applied Research and Training (SMART) project.

\section{Objectives of Health Services Assessment}

- To evaluate the impact of implementing safe motherhood health services interventions on the delivery of health services

- To describe and compare the current readiness of service delivery, staff, and facilities, with the aim of providing quality maternal and neonatal health services to clients compared to current policies and programmes

- To describe the actual quality of care received by the clients

- Training needs assessment of service providers.

\section{Methodology and Sample Strategy}

The SMART Project has a quasi- experimental design. Two districts were selected for the project: District Dera Ghazi Khan as the Intervention District and Layyah as the Control District. Initially, 120 clusters from the Intervention District and 60 clusters from the Control District were sampled through randomized cluster sampling. The baseline HSA was carried out in both DG Khan and Layyah Districts, but the end line HSA was not carried out in Layyah District. Therefore only the findings of HSA in DG Khan District were presented. Since health services interventions in the project were planned for the Government sector, only public health facilities were included in health services assessment.

Dera Ghazi Khan is a large District consisting of three tehsils

- Tehsil DG Khan

- Tehsil Taunsa

- De excluded or Tribal area tehsil

The public sector health delivery system in DG Khan comprises a District Head quarter hospital, a Tehsil head quarter hospital in Taunsa tehsil, 9 Rural Health Centers and 55 Basic Health Units.

Two rounds of surveys were carried out for HSA in Dera Ghazi Khan:

- $\quad$ Baseline HSA (BL)

- Endline HSA (EL) 


\section{Introduction}

For both rounds, all Rural Health Centres (8), Tehsil Headquarters Hospital (1) and the District Headquarters Hospital (1) were selected.

Selection of Basic Health Units (BHUs) differed for baseline and end line HSA. For the baseline HSA, 35 out of a total number of 56 BHUs were selected. The criterion was that BHUs serving the population of 180 sampled clusters were selected. For the endline HSA, 20 BHUs were selected randomly out of $35 \mathrm{BHUs}$ serving the population of 180 sampled clusters, mainly due to resource constraint.

(See Annex I- Sampled Health Facilities)

\section{Research Tools}

Quantitative instruments were designed and developed to carry out data collection. The following five questionnaires were developed for this purpose:

- Inventory of Health Facilities

- Service Provider's Interview

- Observation of client-provider interaction

- Facility-based client exit interviews

- Interviews with women in the community

\section{Inventory of Health Facilities}

This consists of questions regarding the quality of care being provided at the facility, e.g., accessibility, infrastructure, medicines and supplies, instruments and equipment, scope and utilization of services, and staff at the fixed clinic. This was formulated with special reference to reproductive health in general and safe motherhood specifically. The inventory was filled by the team leader who was a medical doctor.

\section{Service Provider Interview}

The respondents of this questionnaire were the service providers of the fixed clinics, e.g., doctors, dispensers, medical technicians, and lady health visitors (LHV). All service providers of a facility, present on the day of visit of research team, were interviewed. It sought information regarding basic qualifications, past trainings/refreshers, job history/experience, and training needs of the respondents. It also contains knowledge based questions related to pregnancy, delivery and neonatal care. The interviewer was again a medical doctor. 


\section{Observation of Client-Provider Interaction}

This captures client-provider interaction during a live consultation through direct observation. The guidelines are based on the principles of CCA, which was one of the major trainings during the intervention phase. Observations were conducted by those who had been trained in Client Centered Approach. An observer used to sit in the consultation room and filled the checklist while observing the interaction between provider and client. The first four clients coming for consultation of a $\mathrm{RH}$ problem were considered for observation.

\section{Facility-Based Exit Interview}

This questionnaire was administered to the female clients who had just had their consultation with one of the service providers. Local interviewers filled this questionnaire, which investigates the quality and scope of services at the facility, as well as the interpersonal skills and behaviour of the provider. Usually two interviewers sat outside the consultation room, and randomly picked the client who came out of the consultation room. They asked some filter questions and the willingness of women before conducting a detailed interview. After the interviewer completed an interview, the very next woman coming out of consultation room was approached and so forth till 4 or 5 clients were interviewed by an interviewer.

\section{Interviews with Women in the Community}

Randomly selected female clients residing in the vicinity of the fixed clinic who had visited the facility within last three months were the subjects for these interviews. While the rest of team stayed on at a facility, two or three members of the research team moved to nearby community and randomly visited surrounded households. They asked filter questions to know whether a married woman of reproductive age was residing in the house and whether she had visited the government health facility (being visited by the research team on that day) during the last three months. The contents of the questionnaires are essentially the same as those of the FacilityBased Exit Interview. Although the respondents for each of the exit instruments were different, the aim was to gauge the difference of perception at both levels.

\section{Data Collection Phase}

\section{Selection of Teams}

The implementation, overall management, and supervision of the HSA component was conducted by the PC manager for HSA. During baseline HSA, three other regular PC staff members were included in the team to carry out data collection, ensure data quality, and assist in logistics. Seven other team members (two medical doctors and five interviewers) were hired locally from DG Khan. For endline HSA, one regular PC staff member was included in a sixmember solitary team, comprising of a medical doctor and five interviewers, all locally hired. 


\section{Introduction}

Local members were hired through informal advertisement by the EDO Health DGK, local PC staff members and other resource persons.

\section{Team Formation}

For baseline HSA, two teams were formed to carry out data collection in DG Khan. Each team was led by a medical doctor and included three female interviewers and one or two regular PC staff members. Thus, there were five members in each team. For endline HSA, a single team was formed, comprising of a PC staff social scientist, four female interviewers, and a local medical doctor (See Annex II- Team Formation)

\section{Training on Research Tools}

Prior training of data collection teams on data collection tools was carried out in DG Khan during both rounds of HSA. For baseline HSA, a five-day training course on the questionnaires was carried out in the Population Council, DG Khan office during January 2004. A one-day trip to tehsil Kot Addu of District Muzaffargarh was also arranged to pre-test the research tools. These instruments were pre-tested in one Rural Health Center (RHC), Sinawan and one BHU (Thatta Gurmani). Two days of refresher training were conducted in the DG Khan Office, just before the start of field data collection in February 2004.

For endline HSA, a four-day training course was conducted in DG Khan during July 2006. This included a visit to local BHU for practice purposes.

\section{Field Work}

For baseline HSA, data collection was started in February 2004 and completed in March 2004. For endline HSA, data collection was done between July and August 2006.

A work plan was developed and distributed among each team member.

One facility was allotted to each team each day; for DHQ and THQ, both teams were combined to work. Teams were also combined for those RHCs that were very busy. The DHQ hospital was covered in two days by both the teams working as a single team.

Each team had a vehicle to facilitate movement in the field. At almost all facilities, the teams reached the facility prior to the first service provider. In case one facility was found closed till 10:30 a.m., the team had an alternate plan to cover another facility. After reaching the facility, two of the female interviewers moved into the community within a five to ten kilometre radius. They were accompanied by the local LHW or Dai of the facility, who would introduce them to the women of the house. 
The inventory was filled by the team leader i.e. the medical doctor, while interviews of the health providers were also usually conducted by the team leader and sometimes by regular PC staff. Observations of Client-Provider interaction were carried out by only those trained in CCA (this includes two PC staff members and the HSA supervisor himself). Facility based client exit interviews and community based client interviews were conducted by female interviewers.

\section{Status of Facilities and data}

Table 1.1: Number of facilities by type included in assessment (both rounds)

\begin{tabular}{lrr}
\hline Facility & Baseline & Endline \\
\hline DHQ & 1 & 1 \\
THQ & 1 & 1 \\
RHCs & 8 & 8 \\
BHUs & 35 & 20 \\
Civil Hospital & 1 & 0 \\
Total & $\mathbf{4 6}$ & $\mathbf{3 0}$ \\
\hline
\end{tabular}

\section{Questionnaires}

Table 1.2: Number of interviews by type in DG Khan

\begin{tabular}{lrr}
\hline Type & Base line & End line \\
\hline Inventory of fixed clinics & 46 & 30 \\
Health Care Provider's interviews & 133 & 96 \\
Facility-based exit interviews & 248 & 235 \\
Community-based exit interviews & 320 & 244 \\
Observations & 202 & 133 \\
Total & $\mathbf{9 4 9}$ & $\mathbf{7 3 8}$ \\
\hline
\end{tabular}




\section{Introduction}

Data was collected in 46 and 30 Health Facilities of DG Khan during baseline and endline HSA respectively. The DHQ in DG Khan was also covered; the sole THQ, which is in Taunsa tehsil, was visited. There are 9 RHCs in District DG Khan and 8 of them were visited because one RHC is in a de-excluded tehsil, and not a part of the project. There were 51 functional BHUs in DG Khan District; 36 BHUs were visited during baseline and 20 during endline HSA. Tehsil wise break up is as follows:

\section{Table 1.3: Tehsil-wise distribution of health care facilities visited}

\begin{tabular}{lrrrrrr}
\hline & \multicolumn{3}{c}{ Name of Tehsil } & \multicolumn{2}{c}{} \\
\cline { 2 - 6 } Facility & \multicolumn{2}{c}{ DG Khan } & \multicolumn{2}{c}{ Taunsa } & \multicolumn{2}{c}{ Total } \\
\hline \multirow{2}{*}{ Baseline } & Endline & Baseline & Endline & Baseline & Endline \\
THQ & 1 & 1 & 0 & 0 & 1 & 1 \\
RHCs & 0 & 0 & 1 & 1 & 1 & 1 \\
BHUs & 6 & 6 & 2 & 2 & 8 & 8 \\
Civil Hospital & 24 & 17 & 11 & 3 & 35 & 20 \\
Total & 1 & 0 & 0 & 0 & 1 & 0 \\
\hline
\end{tabular}

During baseline HSA, a total of 43 Primary Health Care facilities (PHCs ${ }^{1}$ ) were visited. Out of these 43 PHC facilities, 30 are located in Tehsil DG Khan and 13 are in Tehsil Taunsa. Out of a total of 35 BHUs visited, 24 were in DG Khan, while 11 were located in Taunsa

For both baseline and endline HSA, a total of 8 RHCs were visited, 6 in DG Khan and 2 in Taunsa.

As mentioned earlier, all the RHCs (100\%) that currently exist in the two tehsils were visited, while 35 BHUs were visited out of a total 51 BHUs (69\%) for baseline and 20 out of 51 BHUs (39\%) for the endline HSA.

1 PHCs include BHUs and RHCs 


\section{Knowledge of Service Providers: Maternal, Neonatal, and Infant Care}

\section{Introduction}

As discussed in chapter 1, health services interventions comprised of two broad training packages for the health care providers working in the public health facilities: technical training in emergency obstetric care (EmOC) and behavioural training, i.e., Client Centered Approach (CCA). The technical training in EmOC was carried out in two phases. In the first phase, two district teams were trained at the $\mathrm{MCH}$ department of the Pakistan Institute of Medical Sciences (PIMS), Islamabad, in a month-long training course on comprehensive EmOC. These teams comprised of gynaecologists, anaesthetists and operation theatre staff from DHQ in DG Khan and from the private sector (See Annex III - List of trainees comprehensive EmOC). Eight service providers were trained in comprehensive EmOC training at PIMS for one-month duration whereas a total of 104 doctors and paramedics were trained in basic EmOC training of 10 days duration.

In the second phase, the plan was to train all the service providers of the project district, working at DHQs, THQS, RHCs and at BHUs. According to this plan, more than 200 service providers were to be given a 10-day training on basic EmOC. The project trained 112 service providers in basic EmOC. The district health office DG Khan expressed their inability to spare their health staff for a 10 day training programme.

During the baseline HSA, a total of 133 service providers were interviewed to gauge their knowledge regarding maternal, neonatal and infant health. As mentioned above, a total of 112 service providers in DG Khan were trained in EmOC during the intervention phase of the project. (See SMART 2, intervention report). At the endline HSA, a total of 96 service providers were interviewed on the same instruments that had been applied at the baseline. Basically, the service providers were asked four questions, one of each related to pregnancy, delivery, neonatal/infant health and general emergency care.

\section{Characteristics of Interviewed Service Providers}

Overall, more male service providers compared to female service providers who were interviewed, with almost equal proportions in both rounds (64\%:36\%). Less than half (39\%) of the respondents were doctors at the baseline, but their proportion increased to almost $50 \%$ at the endline. The rest were paramedics (Paramedics include Dispensers, medical and health technicians (male/female), LHVs and nurses). 
Table 2.1: Characteristics of respondent s: Health Care Provider interviews

\begin{tabular}{|c|c|c|c|c|}
\hline \multirow[b]{2}{*}{ Variables } & \multicolumn{2}{|c|}{$\begin{array}{l}\text { Baseline } \\
N=133\end{array}$} & \multicolumn{2}{|c|}{$\begin{array}{l}\text { Endline } \\
\mathrm{N}=96\end{array}$} \\
\hline & $\mathbf{N}$ & $\%$ & $\mathbf{N}$ & $\%$ \\
\hline \multicolumn{5}{|l|}{ Gender } \\
\hline Male & 84 & 63.2 & 62 & 64.6 \\
\hline Female & 49 & 36.8 & 34 & 35.4 \\
\hline \multicolumn{5}{|l|}{ Designation } \\
\hline Medical Officer & 52 & 39.1 & 46 & 47.9 \\
\hline LHV/FMT & 28 & 21.0 & 14 & 14.6 \\
\hline Dispenser/HT & 48 & 36.1 & 36 & 37.5 \\
\hline Midwife & 05 & 3.8 & 00 & 0.0 \\
\hline \multicolumn{5}{|c|}{ Category of Service Providers } \\
\hline Male doctor & 39 & 29.3 & 30 & 31.2 \\
\hline Female doctor & 13 & 9.8 & 16 & 16.7 \\
\hline Male paramedic & 48 & 36.1 & 36 & 37.5 \\
\hline Female paramedic & 33 & 24.8 & 14 & 14.6 \\
\hline \multicolumn{5}{|l|}{ Place of Service } \\
\hline $\mathrm{BHU}$ & 82 & 61.6 & 48 & 50.0 \\
\hline $\mathrm{RHC}$ & 36 & 27.1 & 30 & 31.2 \\
\hline Civil Hosp. Sakhi Sarwar & 02 & 1.5 & 00 & 0.0 \\
\hline $\mathrm{THQ}$ & 03 & 2.3 & 07 & 7.3 \\
\hline $\mathrm{DHQ}$ & 10 & 7.5 & 11 & 11.5 \\
\hline \multicolumn{5}{|l|}{ Training Status } \\
\hline Untrained & 133 & 100.0 & 29 & 30.2 \\
\hline Both Tech \& CCA trained & 0 & 0.0 & 30 & 31.3 \\
\hline CCA alone trained & 0 & 0.0 & 37 & 38.5 \\
\hline Number of Respondents & 133 & 100.0 & 96 & 100.0 \\
\hline
\end{tabular}

Among the doctors, there were more male doctors at the baseline (75\%) compared to female doctors $(25 \%)$, while the proportion of male doctors decreased (58\%) towards the endline compared to female doctors $(42 \%)$. 
The proportion of male doctors and male paramedics were almost equal in both rounds (30\% and $37 \%$ ), while there was an increase in the proportion of female doctors from the baseline $(10 \%)$ to endline $(17 \%)$. The proportion of female paramedics decreased at endline $(15 \%)$ compared to baseline $(25 \%)$.

More than half of the interviews were conducted with service providers of BHUs in both the rounds, followed by RHC, DHQ and THQ respectively. Proportionally, slightly more interviews were conducted at DHQ, THQ and RHC towards the endline compared to the baseline, while slightly fewer interviews were conducted at BHUs during the endline survey $(50 \%)$ compared to baseline $(62 \%)$.

Among the 96 service providers who were interviewed at endline, 67 were trained (37 in CCA alone and 30 in both CCA and technical training) and 29 were untrained. Obviously, most of the trained service providers could not be interviewed at the endline survey. One of the reasons was that fewer health facilities were visited at the endline compared to baseline: whichever service provider happened to be available on the day of the visit was interviewed.

\section{Results}

The overall results show that there was a reasonable improvement in the knowledge of service providers regarding maternal and infant care after the intervention. At the endline survey, those who were trained scored higher while answering the questions related to maternal and infant health compared to those who were not trained. Although two types of trainings were imparted, service providers who were trained only in behavioural training (CCA) also showed improvement in their knowledge regarding MNH care, compared to those who were not trained. It has already been mentioned that service providers were first given CCA training and once they are trained in CCA, they received technical training in basic EmOC. The District Health Department could not spare all their service providers for basic EmOC training. That is why some service providers were trained in CCA only but not in basic EmOC and some were able to receive both CCA and basic EmOC. Only eight persons from tertiary care hospitals were trained in comprehensive EmOC training, as planned.

A comparative analysis was done of all respondents at baseline, versus selective groups at end line (untrained, trained in CCA only, trained in both CCA and technical trainings). All the respondents at baseline were analyzed, along with three selective groups at endline. Since no one was trained at the base line, his or her knowledge was considered collectively as baseline. A total number of 133 service providers were interviewed at baseline. 
During the intervention phase, some of these service providers were trained in CCA training as well as in the technical EmOC training, while some received only CCA training. Some of those interviewed at baseline did not receive any training at all. Regardless of who was interviewed for knowledge at baseline, 204 service providers were trained in CCA; of these, 104 were also given technical training. In other words, 100 were trained in CCA only and 104 received both CCA and technical training, while a proportion of the service providers in the district did not receive any training at all.

A total number of 96 service providers were interviewed at endline, of whom a proportion had also been interviewed at baseline. Regardless of whether these endline respondents had been interviewed at baseline or not, a proportion of them were trained in CCA only (37) and a proportion were trained in both CCA and technical training (30); the rest were not trained at all (29).

It is worth mentioning here that a proportion of service providers who were trained in either set of training were not interviewed at both ends and some were present in one of the two rounds (baseline or endline). The same is true for a proportion of service providers who were not trained at all. This information is important to understand the following analysis and the complexity of tracing the true proportions.

\section{Knowledge Regarding Pregnancy}

In this analysis, we took all the service providers at the baseline $(\mathrm{N}=133)$ and matched them with the endline data $(\mathrm{N}=96)$ service providers, who were divided into three groups:

- Untrained (29)

- CCA only trained (37)

- Trained in both CCA and technical training (30).

The overall knowledge of those who were untrained at endline showed a rather negative change in knowledge, if any at all, compared to all the respondents who were interviewed at the start of the project. The proportion of the endline untrained service providers who were unable to mention correctly any of the danger signs of pregnancy ${ }^{2}$ has gone up, while the proportion who were able to mention three or more danger signs has actually gone down, from 71 percent at baseline to 59 percent at endline. Compared to untrained providers at endline, those who were trained in CCA only showed a substantial improvement in their knowledge regarding the danger signs of pregnancy. The proportion of those who could not mention any

\footnotetext{
${ }^{2}$ Danger signs of pregnancy:

Bleeding from vagina, Severe headache, dizziness and blurring of vision, puffiness of the face, hands and feet, fever, lack of normal colour in skin (pallor), Abdominal pain or tenderness
} 
of the danger signs or could only mention one or two had decreased, compared to baseline, while the proportion of those who mentioned more than three danger signs had increased to 76 percent at endline, compared to 71 percent at baseline. This was due to the fact that during the CCA training, the technical aspects of pregnancy, delivery, the postnatal period and infant health were also discussed in detail.

Figure 2.1: Knowledge regarding pregnancy

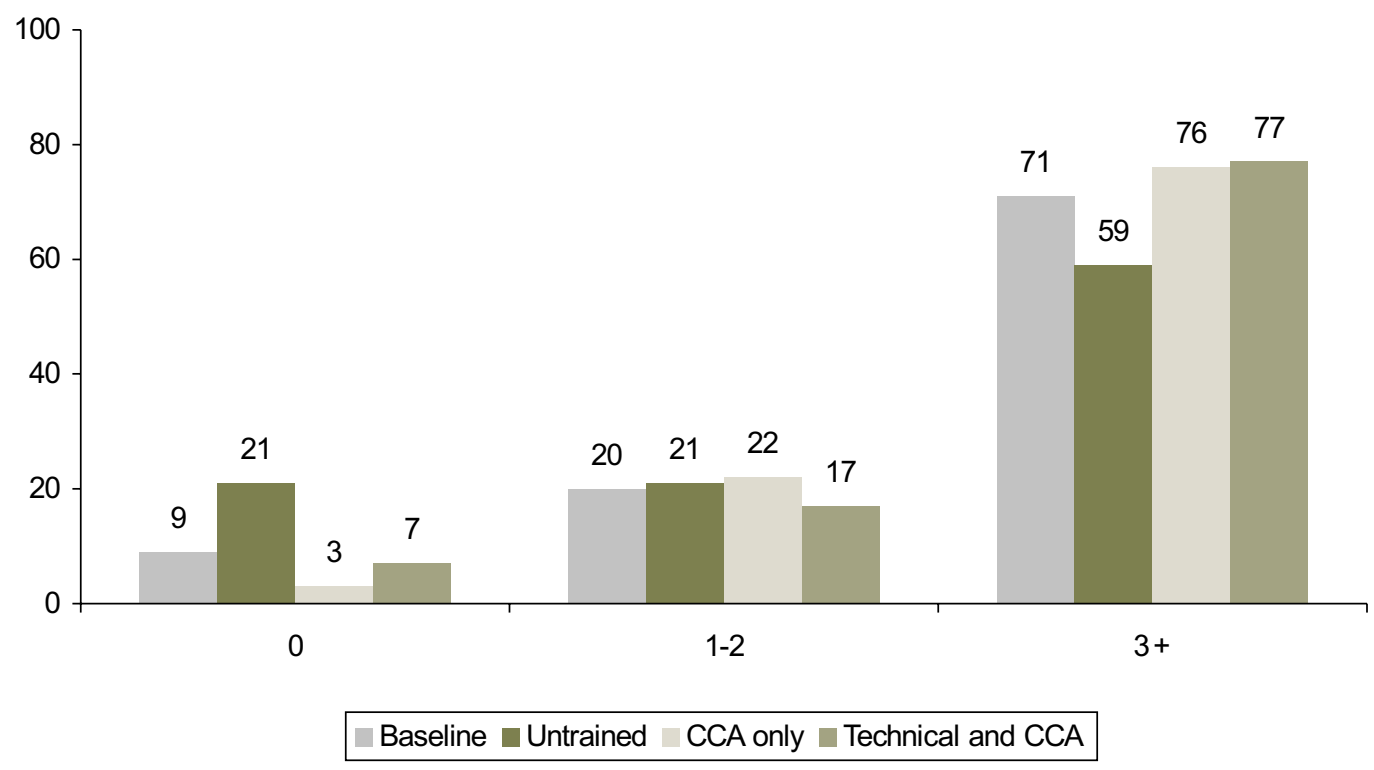

When we analyzed the service providers who were trained in both CCA and technical training towards the endline, although an improved picture was apparent, the improvement is neither as substantial nor as high as had been expected.

One of the reason could be the great dissimilarity in the background variables of the two groups; those trained in both CCA and technical trainings and those who were trained only in CCA responded to the technical questions at the endline HSA. The group who were trained in both CCA and technical trainings constituted 6 (20\%) doctors and 24 (80\%) paramedics; in comparison, the group that got CCA only training had 23 (62\%) doctors (2 were gynaecologists) and $14(38 \%)$ paramedics. In addition, with the former group, only one interview was conducted at DHQ hospital and one at the THQ hospital. The rest were interviewed at RHCs or BHUs. The latter group comprised of service providers of whom a greater proportion were appointed at DHQ hospital (22\%), one at THQ hospital, and the remaining seventy five percent at RHCs or BHUs. Obviously, the doctors are specifically trained and as the DHQ hospital is a secondary centre for management, they are expected to show more knowledge compared to others. Despite all this, there was a positive and definable difference in endline knowledge of those who were given both trainings. 


\section{Knowledge Regarding Delivery}

Service providers were asked to mention the signs of obstructed labour. ${ }^{3}$ Those who were untrained showed no substantial difference when compared to all respondents at baseline. At endline, when the same question was put to those who were trained in CCA only, there was a positive change in proportions. The proportion that could not mention any sign of obstructed labour declined from 28percent at baseline to 16percent at endline. The proportion of those who were able to mention more than four signs increased from 26 percent at baseline to 35percent at endline. When we analyze the group that was trained in basic EmONC, the proportion who were able to mention more than four correct signs of obstructed labour was greater (37\%) than those who were either not trained (31\%) or trained in CCA only (35\%). Again, the background characteristics of those who were not trained at all (mostly doctors and working at large hospitals) were because of their being more knowledgeable initially, compared to those who were trained. Nevertheless, trained service providers had scored high when questioned on their knowledge of delivery compared to untrained service providers.

\section{Figure 2.2: Knowledge regarding delivery}

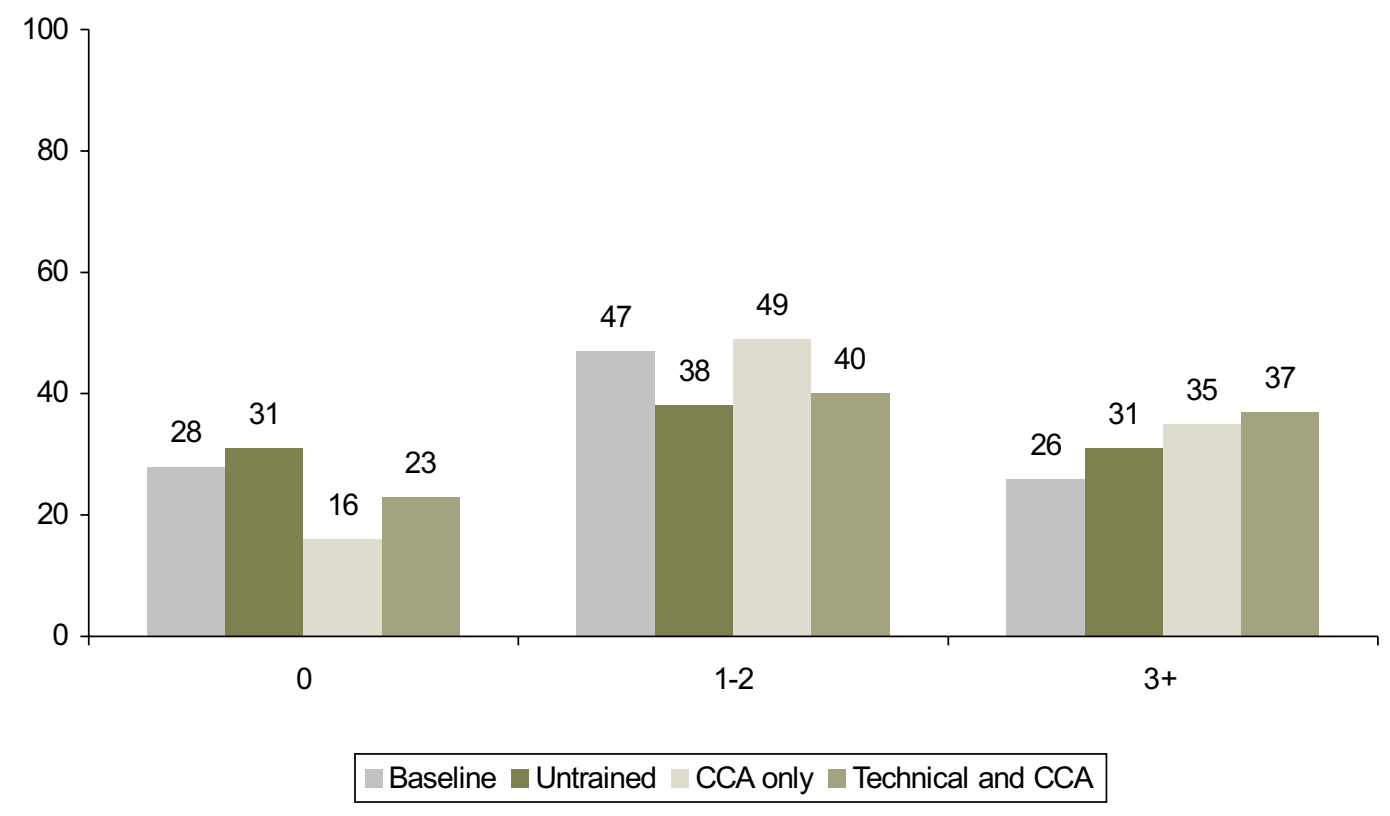

\footnotetext{
${ }^{3}$ Signs of obstructed labour:

No palpable contractions/ infrequent contractions, no change in cervix, large caput, 3rd degree moulding, cervix poorly applied to the presenting part, oedematous cervix, ballooning of lower uterine segment, formation of retraction band (Bandl's ring), less than 3 contractions in 10 minutes each lasting less than 40 seconds, and presentation other than vertex.
} 


\section{Knowledge Regarding Neonatal Health Care}

Most infant deaths occur during the first 24 hours of life, mainly due to non recognition of complications regarding neonatal health. Thus, it is very important to assess the newborn baby for potential life-threatening conditions. During HSA, questions were asked about the assessment of a newborn baby within 24 hours of birth. 4 The proportion of service providers who were able to mention between two to five examinations was 90 percent among those who were trained in basic EmOC and neonatal care, compared to 72 percent among the untrained service providers. In addition to this, all service providers of the trained group were able to mention at least one examination for newborn assessment, while among the untrained group, 14 percent of the respondents were unable to mention any of the examinations carried out to assess the health of a newborn baby within 24 hours of birth.

\section{Figure 2.3: Knowledge regarding infant health}

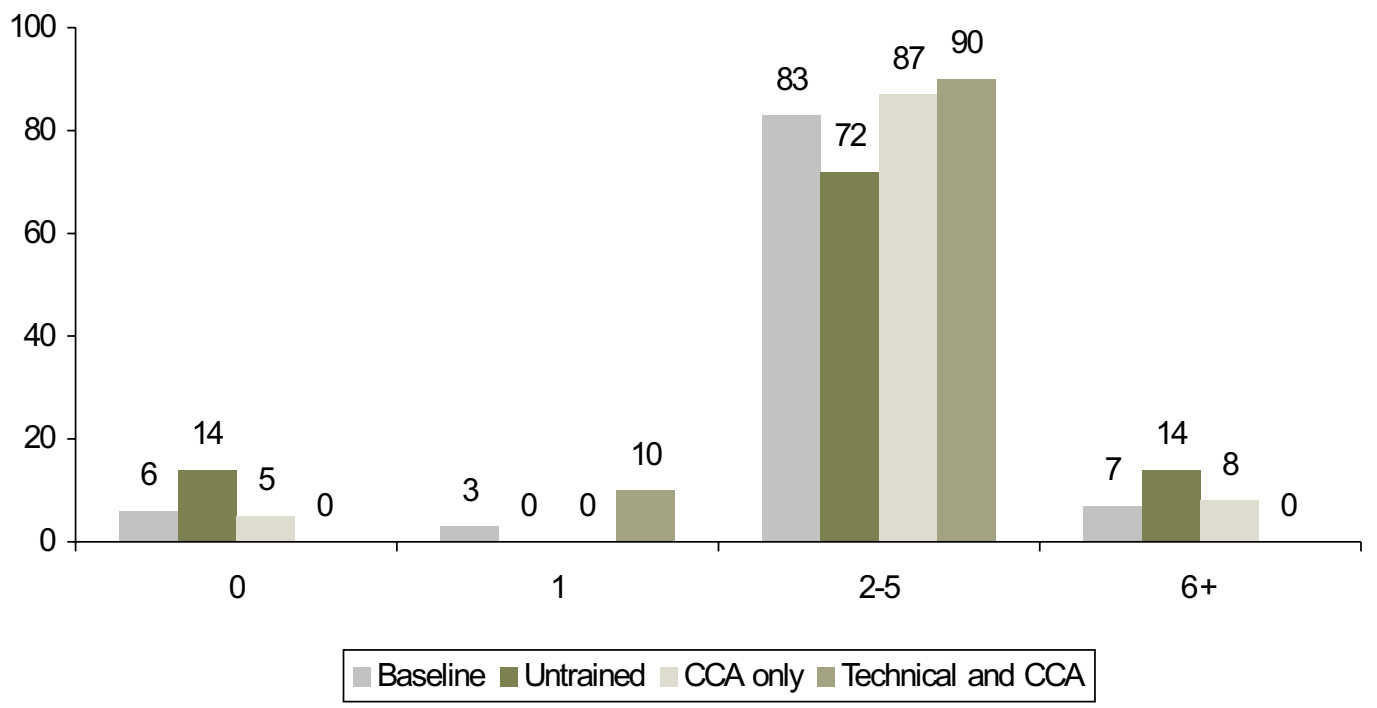

\footnotetext{
${ }^{4}$ Neonatal Health Assessment:

Check for jaundice symptoms, cyanosis, low birth weight, identify defects, urine and stool, breathing, crying, temperature, sucking reflexes, heartbeat/ pulse rate/ heart rate and umbilical cord examination.
} 


\section{Knowledge Regarding Shock Management}

The last question was asked regarding general management of a patient. During emergencies related to obstetric conditions, it is very common for the patients to bleed and succumb to hypovolemic shock and expire if no management is instituted. So it is essential for the service providers to know the steps involved in the management of a patient who is bleeding excessively and is likely to go into shock 5 .

The majority of trained service providers (77percent) were able to mention two to five steps of shock management, compared to 66 percent of those who were not trained, despite the fact that most of the trained were paramedics at PHCs, as opposed to those who were not trained. At baseline ten percent of respondents were unable to mention any of the steps of shock management, whereas after training, the number was zero. It has already been mentioned that some of the indicators improved most for those who got CCA training but no technical training. The reason for this improvement is the inherent discussion on the four questions in the training contents of CCA.

Figure 2.4: Knowledge regarding shock management

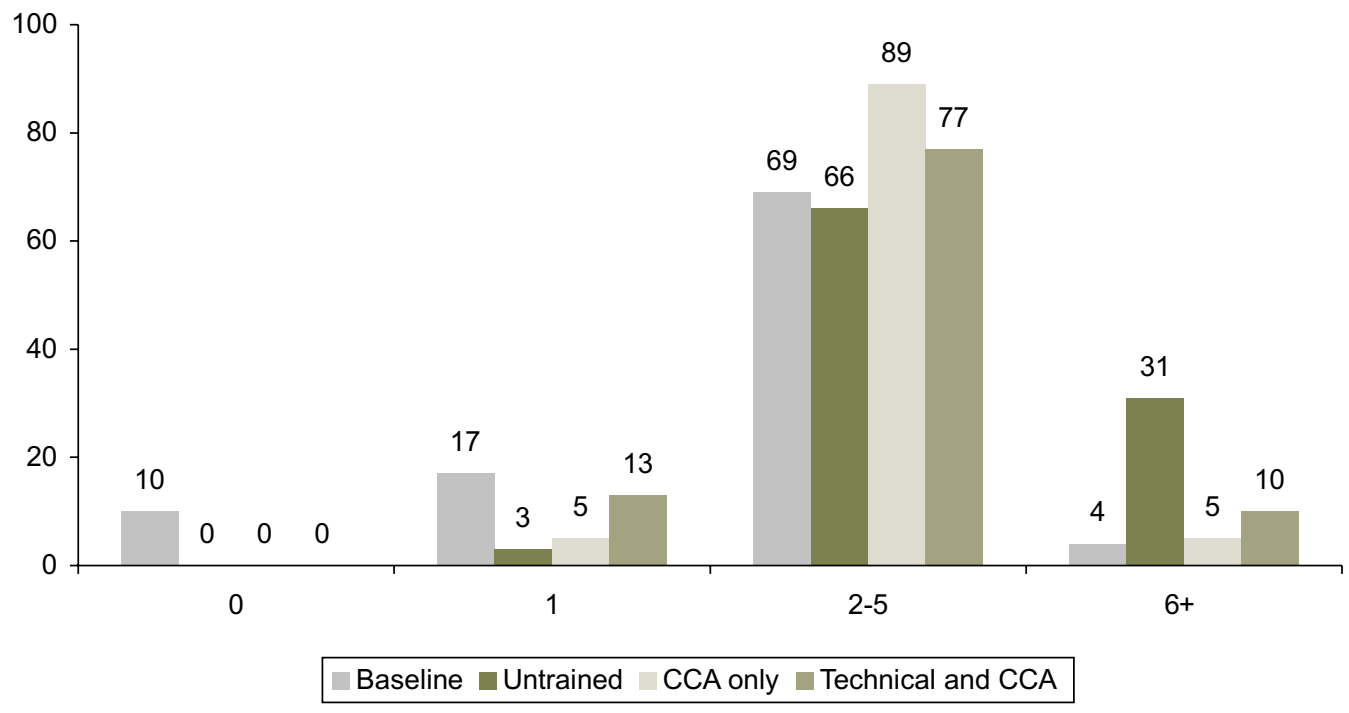

\footnotetext{
5 Shock Management:

Start infusion using large bore canula (14-16G), keep head tilted down / legs elevated, losen clothing, rapidly infuse IV fluid (saline or Ringers solution) at the rate of one litre in 15-20 minutes, give at least 2 litres of IV fluids in first hour, monitor BP, pulse and respiration, keep the patient warm, cross-match and $\mathrm{HB}$, nurse patient in a lateral position, ensure airway is open; arrange for blood, oxygen inhalation, Decadron/ Dexamethasone; assess cause of shock, cardiopulmonary resuscitation, pass Folly's catheter and inotropic drugs (Dopamine/Atropine/ Neacathamide).
} 


\section{Readiness of the District Health Delivery System for Maternal and Neonatal Care}

This chapter compares the situation at service delivery points and attempts to assess to what extent service delivery systems are "ready" to provide quality services, before and after the intervention. At the service delivery point level, readiness to deliver quality care services means that staff is available, trained, and competent to provide services; commodities and equipment are available, functioning and used; and the facility is adequate to handle the client load. In other words, ensuring that the conditions for delivery of quality of services exist.

Although no active intervention was done to upgrade the health facilities, improvements in some of the indicators was expected indirectly as a result of training of service providers and district health managers. An overview and comparison of before and after is important because a positive or negative shift in supplies and infrastructure can influence the services and output indicators accordingly.

\section{Accessibility of Health Facilities}

District and Tehsil Headquarters hospitals are located in the main towns and are easily accessible by road. Most of the Primary Health Care facilities (PHCs), which include both Rural Health Centers (RHCs) and Basic Health Units (BHUs), are connected to a metal road; there is also a main road within five kilometres of the area. The majority is, therefore, accessible to clients. For maternal and neonatal care, the availability of a qualified doctor-particularly of a female doctor-is of paramount importance. BHUs are closed by 2:00 pm, while at most of the RHCs; female doctors are not available in the evening and during the night. So the availability of private doctor with an MBBS degree in the community makes a difference for MNH care. In most of the areas where these PHCs are located, no female doctor is available in the private sector. In a majority of areas where RHCs are located, private male doctors were available, due to the fact that RHCs are usually located in the large towns of the district. But in a majority of the areas where BHUs were located, even a male private practitioner was not available. 
Figure 3.1: Percentage of PHCs connected or near a metalled road and that have private female and male doctors available

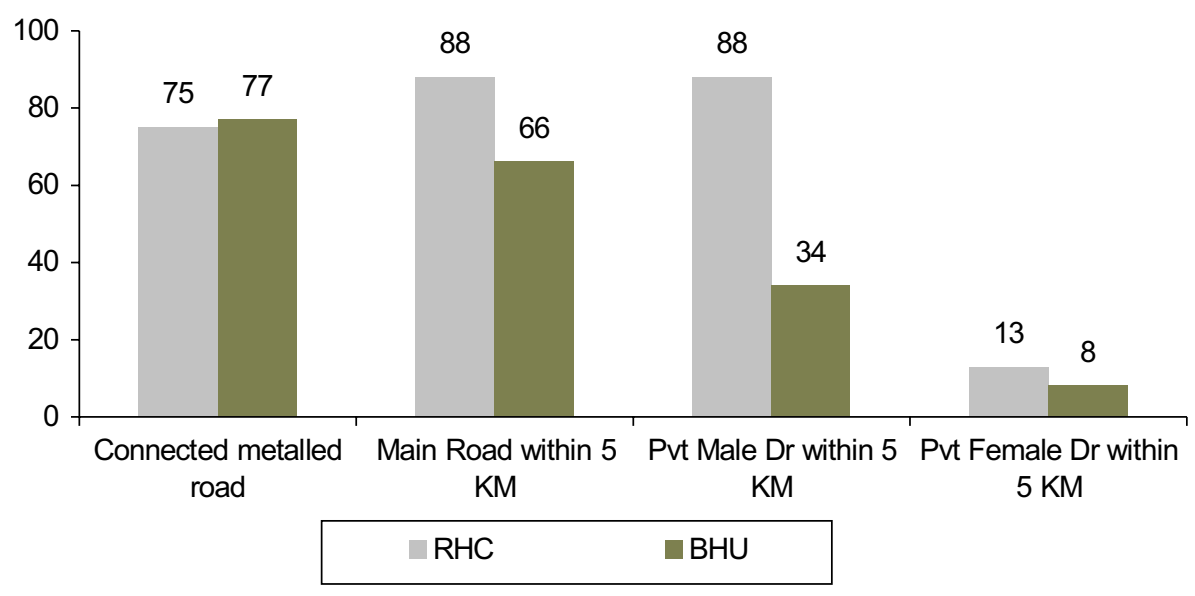

\section{Basic Infrastructure of Fixed Clinics}

Availability of water, electricity, toilet facilities and waiting areas are important indicators of accessibility of clients to these health centres. This is especially true for female clients who come for maternal neonatal and infant care. The overall trend of accessibility and infrastructure indicators is towards improvement but the pace is slow.

The majority of primary care health facilities in the district had the necessary infrastructure in place. However, there were several gaps in the actual functionality of the physical infrastructure.

Table 3.1: Number of health facilities with basic infrastructure in place

\begin{tabular}{lrrrrr}
\hline Indicator & Year & DHQ & THQ & RHC & BHU \\
\hline \multirow{2}{*}{ Piped running water } & 2004 & 1 & 1 & 8 & 18 \\
& 2006 & 1 & 1 & 7 & 9 \\
\multirow{3}{*}{ Electricity } & 2004 & 1 & 1 & 8 & 28 \\
Working toilet for clients & 2004 & 1 & 1 & 7 & 10 \\
available & 2006 & 1 & 1 & 7 & 11 \\
Separate waiting area for & 2004 & 1 & 1 & 3 & 11 \\
female clients & 2006 & 1 & 0 & 5 & 5 \\
Total sampled & & $\mathbf{1}$ & $\mathbf{1}$ & $\mathbf{8}$ & $\mathbf{3 5}$ \\
\hline
\end{tabular}

*20 BHUs were sampled during 2006 round. 
Some indicators have shown improvement during endline health services assessment, compared to baseline assessment. Electricity is now available in almost all health facilities in the district. The majority of health centres had in place working toilets for clients, compared to baseline. Availability of piped running water had slightly decreased for BHUs and RHCs, while separate waiting area in the clinic for female clients was not available at THQ during endline. But it was available at 5 RHCs at endline, compared to at 3 RHCs at baseline.

\section{Medical Examination Facilities}

The consultation room and especially the examination room/areas are important with regard to quality of care and placement of different services. A clean and hygienic environment and adherence to infection prevention protocols ensures health promotion and reduces the risk of introduction or spread of different infections. During the process of consultation and especially during physical examination, maintenance of privacy is essential to gain the confidence of the client, client satisfaction and greater compliance.

\section{Physical Facilities at the Examination Area}

Cleanliness, availability of light, water and examination bed/couch has shown an improvement at the endline assessment. Endline results show that an overwhelming majority of health centres are clean, with availability of adequate light and examination bed/couch.

\section{Table 3.2: Number of health outlets with basic physical facilities in the} examination area

\begin{tabular}{lccccc}
\hline Indicator & Year & DHQ & THQ & RHC & BHU \\
\hline \multirow{2}{*}{ Cleanliness } & 2004 & 1 & 1 & 8 & 17 \\
& 2006 & 1 & 1 & 8 & 16 \\
Adequate light & 2004 & 1 & 1 & 8 & 27 \\
& 2006 & 1 & 1 & 7 & 16 \\
Adequate water & 2004 & 1 & 1 & 8 & 18 \\
& 2006 & 1 & 1 & 7 & 11 \\
Exam bed/couch & 2004 & 1 & 1 & 7 & 20 \\
Total sampled & 2006 & 1 & 1 & 7 & 17 \\
\hline
\end{tabular}

*20 BHUs were sampled during 2006 round. 


\section{Infection Prevention Techniques}

More health facilities were following infection prevention techniques at the endline assessment compared to baseline information. If we look at the four steps of infection prevention procedures (decontamination, cleaning, disinfection and sterilization), there were improvements in observing all four steps at the health facilities, except the BHUs, where step II (cleaning instruments with water and soap) was being observed at half of the BHUs at baseline, compared to at three quarters at endline. Otherwise, the remaining steps have shown an improvement at BHUs. Despite the fact that sterilization facility (autoclave) is available at RHCs, at no RHCs sterilization was being done at baseline; however, at endline, sterilization was implemented in 5 RHCs.

Table 3.3: Number of health facilities following the 4 steps of infection prevention

\begin{tabular}{lrrrrr}
\hline Indicator & Year & DHQ & THQ & RHC & BHU \\
\hline Step I & 2004 & 1 & 1 & 0 & 1 \\
Decontamination & 2006 & 1 & 1 & 8 & 10 \\
Step II & 2004 & 1 & 1 & 7 & 26 \\
Cleaning & 2006 & 1 & 1 & 8 & 11 \\
Step III & 2004 & 1 & 1 & 4 & 13 \\
Disinfection & 2006 & 1 & 1 & 8 & 10 \\
Step 4 & 2004 & 1 & 1 & 0 & 4 \\
Sterilization & 2006 & 1 & 1 & 5 & 2 \\
Total sampled & & $\mathbf{1}$ & $\mathbf{1}$ & $\mathbf{8}$ & $\mathbf{3 5}$ \\
\hline
\end{tabular}

*20 BHUs were sampled during 2006 round. 


\section{Privacy Arrangements in the Examination Area}

Privacy arrangements in the examination area have not shown a substantial change over time. At endline, separate examination rooms were available at all RHCs and more than two-thirds of BHUs, compared to 7 RHCs and 60 percent of BHUs. Approximately half of the PHCs had arrangements for auditory and visual privacy.

\section{Table 3.4: Number of health facilities where necessary arrangements for privacy of the client were maintained}

\begin{tabular}{lrrrrr}
\hline Indicator & Year & DHQ & THQ & RHC & BHU \\
\hline Separate exam & 2004 & 1 & 1 & 7 & 21 \\
room/area & 2006 & 1 & 1 & 6 & 14 \\
Auditory privacy & 2004 & 1 & 0 & 3 & 10 \\
& 2006 & 1 & 1 & 2 & 8 \\
Visual privacy & 2004 & 1 & 1 & 6 & 15 \\
Total sampled & 2006 & 1 & 1 & 5 & 9 \\
\hline
\end{tabular}

*20 BHUs were sampled during 2006 round.

\section{Medicines, their Storage and Record Facilities}

Medicines are purchased by the district health office and are supplied to primary care facilities on a monthly or bimonthly basis. In addition to this, RHCs have their own funds available to purchase some medicines. So the availability of medicines fluctuates over different periods of time. But it does reflect the management and support services of the health delivery system. At the same time, on the part of the health facilities, it is an important indicator of QoC and subsequent client satisfaction. We have divided the list of medicines into several groups and can analyze them in relation to maternal and child health medicines and medicines for other purposes. Overall, endline results reflect a positive trend towards the availability of medicines at the district health outlets, though there were some gaps to be considered.

\section{Medicines to Treat Anaemia}

Haematinics are the medicines required to treat the anaemia in women. It is especially important because a large proportion of women living in DG Khan have shown a low haemoglobin $(\mathrm{Hb})$ level during pregnancy.

A slightly better availability of haematinics (iron tablets, folic acid, multivitamins and vitamin B complex) was noted during endline assessment compared to baseline. But these medicines were still not available at the majority of health outlets in the district. 


\section{Medicines for Obstetric Care}

Endline survey showed an improved availability of medicines for obstetric care compared to baseline health services assessment, although most obstetric care medicines were not available at the majority of health facilities.

\section{Table 3.5: Number of health facilities with availability of medicines to treat} anaemia

\begin{tabular}{lrrrrr}
\hline Indicator & Year & DHQ & THQ & RHC & BHU \\
\hline \multirow{2}{*}{ Ferrous Sulphate } & 2004 & 0 & 0 & 3 & 3 \\
& 2006 & 0 & 0 & 3 & 7 \\
Folic Acid & 2004 & 0 & 0 & 4 & 7 \\
\multirow{2}{*}{ Malt Vitamin } & 2006 & 1 & 0 & 3 & 8 \\
& 2004 & 0 & 0 & 4 & 9 \\
Vitamin B Complex & 2006 & 0 & 0 & 4 & 12 \\
Total sampled & 2004 & 1 & 1 & 6 & 13 \\
\hline
\end{tabular}

*20 BHUs were sampled during 2006 round.

Diazepam and Oxytocin injections were available at 70 percent and 90 percent of the facilities respectively; but only a few (1 to 3 facilities) had injections of Potassium Chloride, Calcium Gluconate and Prostaglandin $\mathrm{E}_{2}\left(\mathrm{PGE}_{2}\right)$. No facility in the district had injections of Sodium Bicarbonate and Magnesium Sulphate. 
Table 3.6: Number of facilities with availability of necessary maternal health medicines

\begin{tabular}{lrrrrr}
\hline Indicator & Year & DHQ & THQ & RHC & BHU \\
\hline Diazepam & 2004 & 1 & 0 & 1 & 5 \\
& 2006 & 0 & 1 & 8 & 17 \\
Oxytocin injection & 2004 & 0 & 0 & 2 & 1 \\
& 2006 & 0 & 0 & 8 & 12 \\
Prostaglandin E2 & 2004 & 0 & 0 & 0 & 0 \\
\multirow{3}{*}{ Injection Calcium } & 2006 & 0 & 0 & 0 & 3 \\
Gluconate & 2004 & 0 & 0 & 0 & 0 \\
Injection Sodium & 2006 & 1 & 0 & 0 & 3 \\
Bicarbonate & 2004 & 0 & 0 & 0 & 0 \\
Inj Potassium Chloride & 2004 & 0 & 0 & 0 & 0 \\
Injection Magnesium & 2006 & 1 & 0 & 0 & 1 \\
Sulphate & 2004 & 1 & 0 & 0 & 1 \\
Total sampled & & 0 & 0 & 0 & 2 \\
\hline
\end{tabular}

*20 BHUs were sampled during 2006 round.

\section{Antibiotics}

Availability of antibiotics did not show an improvement over time at the health centres. Endline survey shows that oral antibiotics and injectable antibiotics were available at slightly more than two-thirds of the BHUs and at all RHCs. Availability of injectable antibiotics was slightly better at endline, with availability at around 86 percent of health facilities, compared to 80 percent at baseline.

\section{Table 3.7: Number of health facilities with available antibiotics}

\begin{tabular}{lrrrrr}
\hline Indicator & Year & DHQ & THQ & RHC & BHU \\
\hline \multirow{2}{*}{ Oral Antibiotics } & 2004 & 1 & 1 & 8 & 27 \\
& 2006 & 1 & 1 & 7 & 11 \\
Parental Antibiotics & 2004 & 1 & 1 & 8 & 27 \\
Total sampled & 2006 & 1 & 1 & 8 & 16 \\
\hline
\end{tabular}

*20 BHUs were sampled during 2006 round. 


\section{Intravenous Fluids}

The availability of 5\% dextrose water showed a downward trend, with availability at less than half of the facilities at endline, compared to its availability at two thirds of district health facilities during baseline survey. However, availability of dextrose saline and normal saline showed an increase, and were available at almost half of the district health outlets. Slightly more than half of district health outlets were without IV fluids at the endline.

Intravenous fluids are among the essential life-saving drugs and they have a special role in emergency situations, such as shock due to loss of blood or body fluids. These situations are so often encountered by married women of reproductive age and by infants. The WHO recommends that these fluids should be available at all health centres.

\section{Table 3.8: Number of health facilities with availability of important intravenous} fluids

\begin{tabular}{llrrrr}
\hline Indicator & Year & DHQ & THQ & RHC & BHU \\
\hline \multirow{2}{*}{ 5\% Dextrose water } & 2004 & 1 & 1 & 6 & 27 \\
& 2006 & 0 & 1 & 5 & 7 \\
\multirow{2}{*}{ Dextrose saline } & 2004 & 1 & 1 & 4 & 7 \\
Normal saline & 2006 & 1 & 1 & 4 & 9 \\
& 2004 & 1 & 0 & 3 & 3 \\
Inj. Glucose 50\% & 2006 & 1 & 1 & 6 & 9 \\
Total sampled & 2004 & 0 & 0 & 0 & 0 \\
*20 BHUs were sampled during 2006 round. & 0 & 0 & 0 & 0 \\
\end{tabular}

\section{Oral Rehydration Salts (ORS)}

Availability of ORS has decreased at the health facilities over time. At baseline, half of the facilities had a supply of ORS, but at endline approximately one third of primary health care facilities had a supply of ORS.

Table 3.9: Number of health facilities where ORS was available

\begin{tabular}{lrrrrr}
\hline Indicator & Year & DHQ & THQ & RHC & BHU \\
\hline \multirow{2}{*}{ ORS } & 2004 & 1 & 1 & 3 & 18 \\
\multirow{2}{*}{ Total sampled } & 2006 & 0 & 1 & 3 & 7 \\
\hline
\end{tabular}

*20 BHUs were sampled during 2006 round. 


\section{Other Medicines}

Availability status for most of medicines used for general ailments and specific conditions showed a downward trend compared to baseline status. Although antacids, anti-emetics, antispasmodics, and anti-hypertensive medicines were available at the majority of health outlets (endline survey), metronidazole, anti-allergic and antihelmenthic medicines were available only at approximately one-third of the facilities. Medicines for treating tuberculosis (TB) were available at half of the facilities visited, while medicines for treating diabetes were virtually non available at primary health facilities.

These medicines are not only important for general patients but are also used to treat women with different complaints and conditions during pregnancy. Some of these are important to treat infant and childhood diseases. Availability of these medicines is essential for more service utilization, greater client satisfaction and compliance, especially for mothers.

Endline assessment results show a severe shortage of anti malarial medication at the majority of district health facilities. These were available at only a third of facilities, compared to their availability at 84 percent of health facilities at baseline HSA. This was despite the fact that endline HSA was conducted during the rainy season (July, August), compared to baseline has, that was conducted during the spring of 2004 (February and March).

Table 3.10: Number of health facilities with availability of important medicines for general patients

\begin{tabular}{lrrrrr}
\hline Indicator & Year & DHQ & THQ & RHC & BHU \\
\hline Metronidazole & 2004 & 1 & 1 & 7 & 26 \\
tablets/Injection & 2006 & 1 & 1 & 4 & 6 \\
Anti-allergics & 2004 & 1 & 1 & 6 & 20 \\
& 2006 & 1 & 1 & 3 & 7 \\
Anti-emetics & 2004 & 1 & 0 & 7 & 28 \\
& 2006 & 1 & 1 & 7 & 12 \\
Anti-helminthics & 2004 & 1 & 0 & 6 & 26 \\
Anti-hypertension & 2006 & 0 & 1 & 1 & 7 \\
drugs & 2004 & 1 & 0 & 5 & 2 \\
Anti-tuberculosis & 2006 & 1 & 1 & 6 & 10 \\
& 2006 & 0 & 1 & 6 & 21 \\
& & 0 & 1 & 6 & 8
\end{tabular}




\begin{tabular}{lrrrrr}
\hline Indicator & Year & DHQ & THQ & RHC & BHU \\
\hline \multirow{2}{*}{ Anti-diabetic drugs } & 2004 & 1 & 1 & 2 & 8 \\
& 2006 & 0 & 1 & 1 & 1 \\
Antacids & 2004 & 1 & 0 & 3 & 24 \\
\multirow{2}{*}{ Anti-spasmodics } & 2006 & 1 & 1 & 7 & 14 \\
& 2004 & 1 & 0 & 7 & 29 \\
Analgesics & 2006 & 0 & 1 & 7 & 10 \\
& 2004 & 1 & 1 & 8 & 25 \\
Chloroquine & 2006 & 1 & 1 & 7 & 19 \\
Total sampled & 2004 & 1 & 1 & 3 & 30 \\
*20 BHUs were sampled during 2006 round. & 1 & 1 & 1 & 8 \\
& & $\mathbf{1}$ & $\mathbf{1}$ & $\mathbf{8}$ & $\mathbf{3 5}$ \\
\hline
\end{tabular}

\section{Other Material/Supplies}

Availability of dressing and bandage materials improved, with availability at all health facilities; injections for local anaesthesia were available at slightly more than a third of the facilities (endline) compared to baseline availability at half the health facilities.

Table 3.11: Number of health facilities with availability of dressing material

\begin{tabular}{lrrrrr}
\hline Indicator & Year & DHQ & THQ & RHC & BHU \\
\hline Dressing & 2004 & 1 & 1 & 8 & 32 \\
material/bandages & 2006 & 1 & 1 & 8 & 20 \\
& 2004 & 1 & 1 & 6 & 17 \\
Local anaesthetics & 2006 & 0 & 1 & 3 & 7 \\
Total sampled & & $\mathbf{1}$ & $\mathbf{1}$ & $\mathbf{8}$ & $\mathbf{3 5}^{*}$ \\
\hline
\end{tabular}

*20 BHUs were sampled during 2006 round. 


\section{Medicine Storage Facilities}

Medicine storage and maintenance facilities were adequate at the baseline assessment and they had further improved as shown by the endline results. At endline, almost all the health facilities had adequate medicine storage facilities and were maintaining records.

\section{Table 3.12: Number of health facilités with adequate storage conditions}

\begin{tabular}{llrrrr}
\hline Indicator & Year & DHQ & THQ & RHC & BHU \\
\hline Adequate storage & 2004 & 1 & 1 & 1 & 26 \\
conditions & 2006 & 1 & 1 & 1 & 18 \\
According to expiry & 2004 & 1 & 1 & 1 & 29 \\
date & 2006 & 1 & 1 & 1 & 19 \\
Total sampled & & $\mathbf{1}$ & $\mathbf{1}$ & $\mathbf{8}$ & $\mathbf{3 5}^{*}$ \\
\hline *20 BHUs were sampled during 2006 round & & & &
\end{tabular}

\section{Medical Equipment}

Different types of medical and surgical instruments and equipment are sanctioned for primary and secondary health care facilities. Although the provision is slightly different for DHQs, THQs, RHCs and BHUs, there are many overlapping segments and in this survey we have analyzed the lists, which are common to all levels.

\section{Maternal health equipment}

There was a positive trend in the availability of maternal health equipment at health facilities of the district. D\&C sets, delivery kits, pairs of gloves, and delivery tables were available at more than three quarters of the primary health facilities at the time of endline assessment.

SMART project has specifically focused on maternal and neonatal health. Safe delivery practices at the institutional levels were emphasized during training of static facilities staff and district health managers. The positive trend could be due to these interventions, but to achieve the indicators of reduced maternal and neonatal mortality, availability of maternal health equipment at all the district outlets is required. 
Table 3.13: Number of facilities with necessary equipment for maternal health care

\begin{tabular}{lccccr}
\hline Indicator & Year & DHQ & THQ & RHC & BHU \\
\hline \multirow{2}{*}{ D \& C set } & 2004 & 1 & 1 & 5 & 21 \\
& 2006 & 1 & 1 & 3 & 14 \\
Midwifery kit or dai kit & 2004 & 1 & 1 & 4 & 21 \\
& 2006 & 1 & 1 & 5 & 16 \\
Pair of gloves & 2004 & 1 & 1 & 2 & 8 \\
\multirow{3}{*}{ Delivery tables } & 2006 & 1 & 1 & 6 & 18 \\
\multirow{3}{*}{ Episiotomy scissors } & 2004 & 1 & 1 & 7 & 23 \\
& 2006 & 1 & 1 & 7 & 15 \\
C- Section set & 2004 & 1 & 1 & 7 & 12 \\
Total sampled & 2006 & 1 & 1 & 6 & 13 \\
\hline
\end{tabular}

*20 BHUs were sampled during 2006 round.

\section{Child Health Equipment}

Availability of child health equipment at the health facilities demonstrated an overall improvement at endline compared to baseline. But the availability was still scarce in the district. Only seven facilities (all RHCs) had infant suction tubes while neonatal intubation sets were available at only four RHCs. These are very important for the treatment of infant and newborn emergencies and other conditions.

\section{Table 3.14: Number of health facilities with necessary equipment for child health} care

\begin{tabular}{lrrrrr}
\hline Indicator & Year & DHQ & THQ & RHC & BHU \\
\hline \multirow{2}{*}{ Baby weighing scale } & 2004 & 1 & 1 & 5 & 21 \\
& 2006 & 1 & 1 & 4 & 14 \\
\multirow{3}{*}{ Infant suction tube } & 2004 & 1 & 1 & 1 & 4 \\
\multirow{4}{*}{ Neonatal Intubation set } & 2006 & 1 & 1 & 2 & 5 \\
Total sampled & 2004 & 1 & 1 & 0 & 2 \\
\hline
\end{tabular}

*20 BHUs were sampled during 2006 round. 


\section{Emergency Equipment}

Availability of all equipment related to the management of emergencies at the health facilities has shown an improvement in the positive direction. Although oxygen cylinders, suction machines, Foley's catheters, and suturing material were available at two-thirds of the facilities (endline survey), amboo resuscitator was only available at twenty-five percent of these facilities. All of these are very basic emergency equipment and it is usually recommended that they should be available at all primary care facilities.

\section{Table 3.15: Number of health facilitieswith necessary equipment for emergency} care

\begin{tabular}{lrrrrr}
\hline Indicator & Year & DHQ & THQ & RHC & BHU \\
\hline \multirow{2}{*}{ Amboo resuscitator } & 2004 & 1 & 1 & 2 & 3 \\
& 2006 & 1 & 1 & 2 & 5 \\
Oxygen cylinder & 2004 & 1 & 1 & 7 & 27 \\
Foley's catheter & 2006 & 1 & 1 & 5 & 17 \\
\multirow{3}{*}{ IV Infusion set } & 2004 & 1 & 1 & 5 & 22 \\
\multirow{2}{*}{ Needle suture cutting } & 2006 & 1 & 0 & 4 & 14 \\
straight & 2004 & 1 & 1 & 8 & 28 \\
Suction machine & 2006 & 1 & 1 & 6 & 14 \\
Total sampled & 2006 & 1 & 1 & 5 & 13 \\
\hline
\end{tabular}

*20 BHUs were sampled during 2006 round. 


\section{General Use Equipment}

Availability of most of the general use equipment has increased at the district health outlets as measured during the endline survey. Despite the fact that this equipment was now available at a vast majority of outlets ( $71 \%$ to $89 \%$ ), the nature of these is so basic (stethoscope, BP apparatus, thermometer, tongue depressor) that they are supposed to be available universally. At the time of the endline survey, disposable syringes were available at only four health facilities, compared to a majority (three-quarters) of the facilities at baseline survey.

Table 3.16: Number of health facilities with necessary equipment for general use

\begin{tabular}{|c|c|c|c|c|c|}
\hline Indicator & Year & DHQ & THQ & RHC & BHU \\
\hline \multirow{2}{*}{ BP apparatus } & 2004 & 1 & 1 & 6 & 13 \\
\hline & 2006 & 1 & 1 & 7 & 18 \\
\hline \multirow{2}{*}{ Stethoscope } & 2004 & 1 & 1 & 5 & 24 \\
\hline & 2006 & 1 & 1 & 5 & 18 \\
\hline \multirow{2}{*}{ Thermometer } & 2004 & 1 & 1 & 5 & 16 \\
\hline & 2006 & 1 & 1 & 6 & 16 \\
\hline \multirow{2}{*}{ Tongue depressor } & 2004 & 1 & 1 & 5 & 23 \\
\hline & 2006 & 1 & 1 & 6 & 14 \\
\hline \multirow{2}{*}{ Sterilizer } & 2004 & 1 & 1 & 6 & 8 \\
\hline & 2006 & 1 & 1 & 8 & 14 \\
\hline \multirow{2}{*}{ Disposable syringes } & 2004 & 1 & 1 & 8 & 27 \\
\hline & 2006 & 1 & 1 & 1 & 3 \\
\hline \multirow{2}{*}{ Weighing scale } & 2004 & 1 & 1 & 8 & 16 \\
\hline & 2006 & 1 & 1 & 7 & 18 \\
\hline \multirow{2}{*}{ Microscope } & 2004 & 1 & 1 & 8 & 22 \\
\hline & 2006 & 1 & 1 & 6 & 16 \\
\hline \multirow{2}{*}{ Functional slides } & 2004 & 1 & 1 & 6 & 27 \\
\hline & 2006 & 1 & 0 & 8 & 14 \\
\hline Total sampled & & 1 & 1 & 8 & $35^{*}$ \\
\hline
\end{tabular}




\section{Accessories for safe motherhood}

Availability of primary furniture for safe motherhood services at the health facilities has improved to a great extent compared to baseline availability. An overwhelming majority possessed the delivery table, examination couch and at least one bed. This shows a better supply of equipment by the district office compared to the situation during the baseline. District health managers were oriented to leadership and Client Centered Services, specifically in the $\mathrm{RH}$ context. The focus of international and national partners also played a part.

Table 3.17: Number of health facilities with necessary accessories for MCH services

\begin{tabular}{lrrrrr}
\hline Indicator & Year & DHQ & THQ & RHC & BHU \\
\hline \multirow{2}{*}{ Examination couch } & 2004 & 1 & 1 & 8 & 29 \\
& 2006 & 1 & 1 & 8 & 19 \\
Baby cots & 2004 & 1 & 1 & 4 & 10 \\
\multirow{3}{*}{ Beds (at least one) } & 2006 & 1 & 1 & 6 & 14 \\
\multirow{3}{*}{ OT table } & 2004 & 1 & 1 & 8 & 31 \\
\multirow{3}{*}{ Sterilized dressing } & 2006 & 1 & 1 & 8 & 20 \\
\multirow{2}{*}{ Stretcher } & 2004 & 1 & 1 & 5 & 2 \\
& 2006 & 1 & 1 & 4 & 4 \\
Wheelchair & 2006 & 1 & 0 & 3 & 4 \\
Total sampled & 2004 & 1 & 1 & 4 & 7 \\
\hline
\end{tabular}

*20 BHUs were sampled during 2006 round. 


\section{Services Available at Fixed Clinics}

Services at the primary and secondary care health facilities are described under following sections:

1. Staff at health facilities

2. Availability of services

3. Monthly record of patients

\section{Staff at health facilities}

This section describes initially the general profile and staffing pattern of service providers at the visited facilities and later on gives a presence status of staff on the day of research team visit to the facility.

Table 3.18: General profile of service providers at visited primary health care facilities

\begin{tabular}{|c|c|c|c|c|}
\hline & Baseline & $\mathrm{N}=43$ & Endline & $\mathrm{N}=\mathbf{2 8}$ \\
\hline Variables & $\mathrm{N}$ & $\%$ & $\mathrm{~N}$ & $\%$ \\
\hline \multicolumn{5}{|l|}{ Gender } \\
\hline Male & 124 & 68.0 & 76 & 63.0 \\
\hline Female & 58 & 32.0 & 45 & 37.0 \\
\hline Total & 182 & 100.0 & 121 & 100.0 \\
\hline \multicolumn{5}{|l|}{ Designation } \\
\hline Medical Officer & 59 & 32.4 & 44 & 39.0 \\
\hline LHV/FMT & 45 & 24.7 & 28 & 24.0 \\
\hline Dispenser/MT/HT & 78 & 42.9 & 42 & 37.0 \\
\hline Total & 182 & 100.0 & 114 & 100.0 \\
\hline \multicolumn{5}{|l|}{$\begin{array}{l}\text { Presence status } \\
\text { (Present on day of visit) }\end{array}$} \\
\hline Male doctors & 50 & 27.0 & 34 & 28.0 \\
\hline Female doctors & 9 & 5.0 & 12 & 10.0 \\
\hline Male paramedics & 78 & 43.0 & 46 & 38.0 \\
\hline Female paramedics & 45 & 25.0 & 29 & 24.0 \\
\hline Total & 182 & 100.0 & 121 & 100.0 \\
\hline \multicolumn{5}{|l|}{ Residential Status } \\
\hline Within hospital premises & 25 & 14.0 & 21 & 19.0 \\
\hline Within same village & 41 & 23.0 & 16 & 14.0 \\
\hline Outside the village & 113 & 63.0 & 76 & 67.0 \\
\hline Total & 179 & 100.0 & 113 & 100.0 \\
\hline \multicolumn{5}{|c|}{ Years since basic qualification } \\
\hline $0-5$ years & 13 & 10.0 & 13 & 15.0 \\
\hline $6-10$ years & 19 & 17.0 & 13 & 15.0 \\
\hline$>10$ years & 84 & 73.0 & 59 & 70.0 \\
\hline Total & 116 & 100.0 & 85 & 100.0 \\
\hline
\end{tabular}




\section{Service providers appointed at the health facilities}

Majority of PHCs were well staffed. Almost all the RHCs had a full team of service providers, while more than two-thirds of BHUs had a full team of service providers at baseline.

By a full team, we mean for an RHC at least one Senior MO, one MO, one female doctor, one $\mathrm{LHV} / \mathrm{FMT}$, and one dispenser. For a BHU, a team comprising of a doctor, one male paramedic, and at least one female paramedic was considered as "all service providers". Among the designated service providers, SMO and WMO are appointed only at RHCs, so the figure shows a single bar for RHCs only. Staffing has improved further at endline, with the inclusion of some female doctors at the BHUs and at THQ Taunsa.

Figure 3.2: Percentage of PHCs with complete team of service providers (baseline)

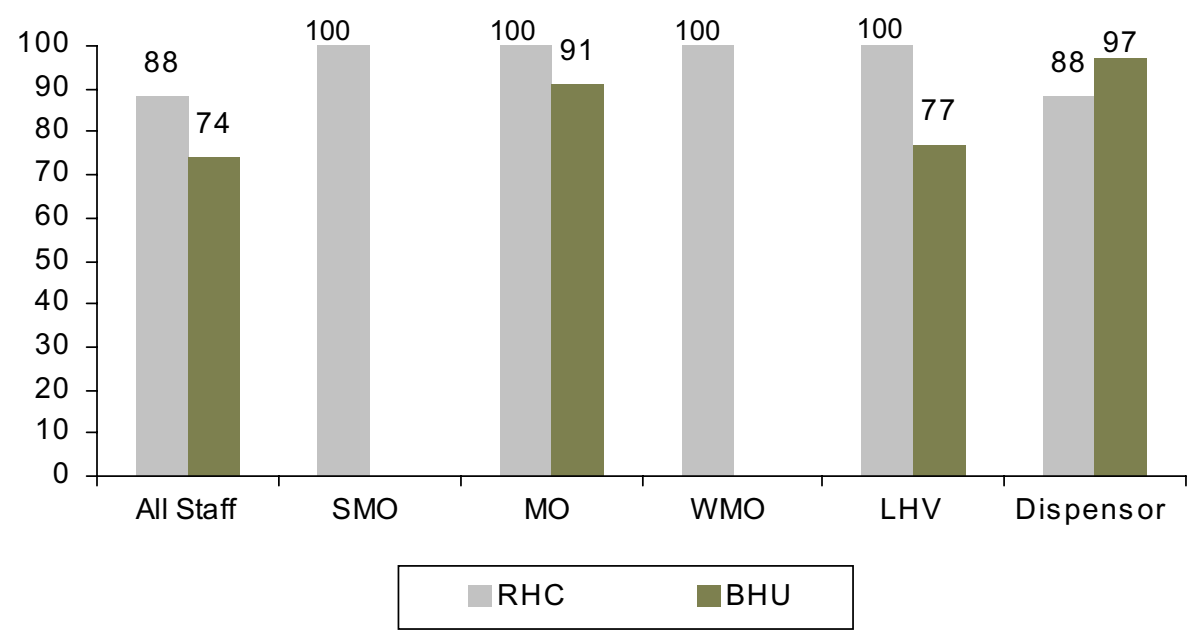

\section{Service providers present on the day of visit}

At most of the RHCs and BHUs, service providers were present on the day the research team visited. The majority of cadres were present at all RHCs of the district at the baseline survey, while at approximately one third of BHUs, an $\mathrm{MO}$ and a dispenser were not available on the day of the visit; and female paramedics was available in half of the visited BHUs on the day data was collected. 
Figure 3.3: Percentage of PHCs with present service providers on the day of visit (baseline)



\section{Availability of services}

\section{BHUs}

Availability of services has generally increased at BHUs between the baseline and endline assessments. Immunization services were available at all BHUs by endline while immunization was available at more than three-quarters of all BHUs when baseline assessment was carried out. However there were lesser BHUs that were providing nutritional and growth monitoring services at the end line. This was probably due to the termination of some programmes (e.g. World Food Program) at the time of endline survey.

Figure 3.4: Percentage of BHUs where different child health services were available- BL vs. EL

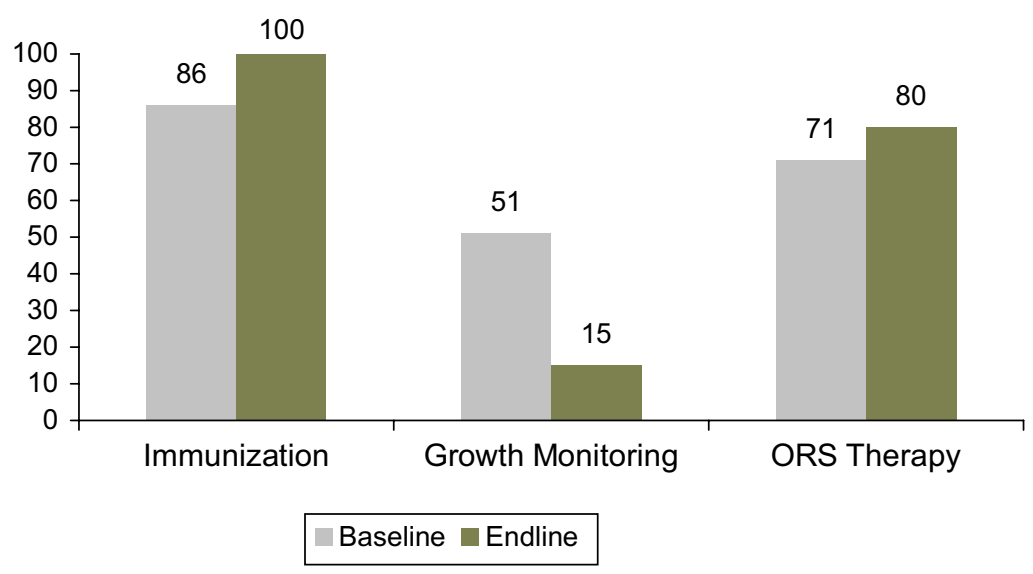




\section{RHCs}

Number of RHCs where specific maternal health services were available had decreased towards the endline. Ambulance was available at 6 RHCs while separate labour room was available at only 3 RHCs.

Figure 3.5: Number of RHC having services related to maternal health, at baseline and endline



Facilities and services at DHQ and THQ

Table 3.19: Availability of specialized services related to maternal health at DHQ and THQ

\begin{tabular}{c|l|c|c}
\hline Serial No. & Services & DHQ & THQ \\
\hline 1 & Complete comprehensive EmOC & $\checkmark$ & $\times$ \\
\hline 2 & Caesarian section & $\checkmark$ & $\checkmark$ \\
\hline 3 & Post-abortion care & $\checkmark$ & $\checkmark$ \\
\hline 4 & Blood bank & $\checkmark$ & $\times$ \\
\hline 5 & Ultrasonography & $\times$ & $\times$ \\
\hline 6 & General surgery & $\checkmark$ & $\checkmark$ \\
\hline
\end{tabular}




\section{Monthly Record of Patients}

The research teams visiting health facilities collected information from the facility records about the number of patients who had visited each facility during the previous month (last complete month before HSA was carried out). Overall information shows an improvement in the number of patients attending public health facilities during the month prior to the survey when baseline and endline information was compared.

\section{Primary Health Care Facilities}

Primary health care facilities include both RHCs and BHUs. As mentioned earlier, 8 RHCs were visited in both rounds while 35 BHUs were visited at baseline and 20 at endline.

\section{Child Health Services}

Primary Health Care facilities provide a number of child health services, including immunization, growth monitoring, ORS therapy and treatment of common childhood conditions. Facility records show that, on average, 53 children had attended a primary health facility during the one month previous to HSA; this increased to 138 per facility per month. Similarly, clients for ORS therapy had doubled when baseline and endline information was compared.

Figure 3.6: Average number of cases for immunization and ORS therapy at PHCs during one month (Baseline: January 2004. Endline: June 2006)

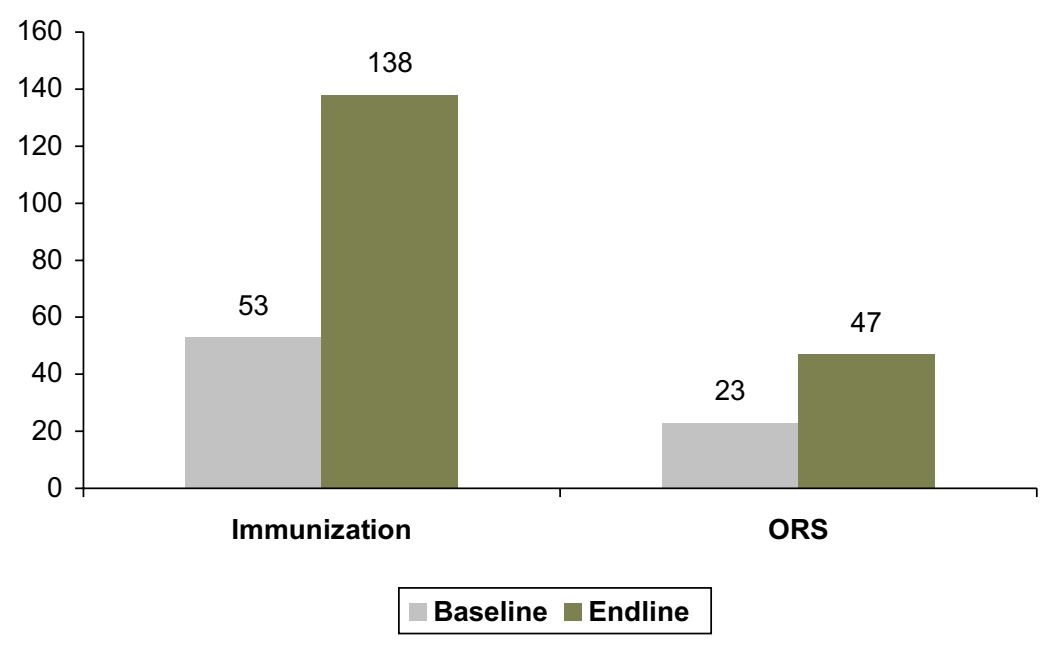




\section{Maternal Health Services}

The average number of women attending PHCs for maternal health care showed an increase over time according to facility records. This is more so for TT vaccination than for any other service. The number of ANC clients remained almost the same.

Figure 3.7: Average number of cases for mate rnal health care at PHC during one month (Baseline: January 2004. Endline: June 2006)

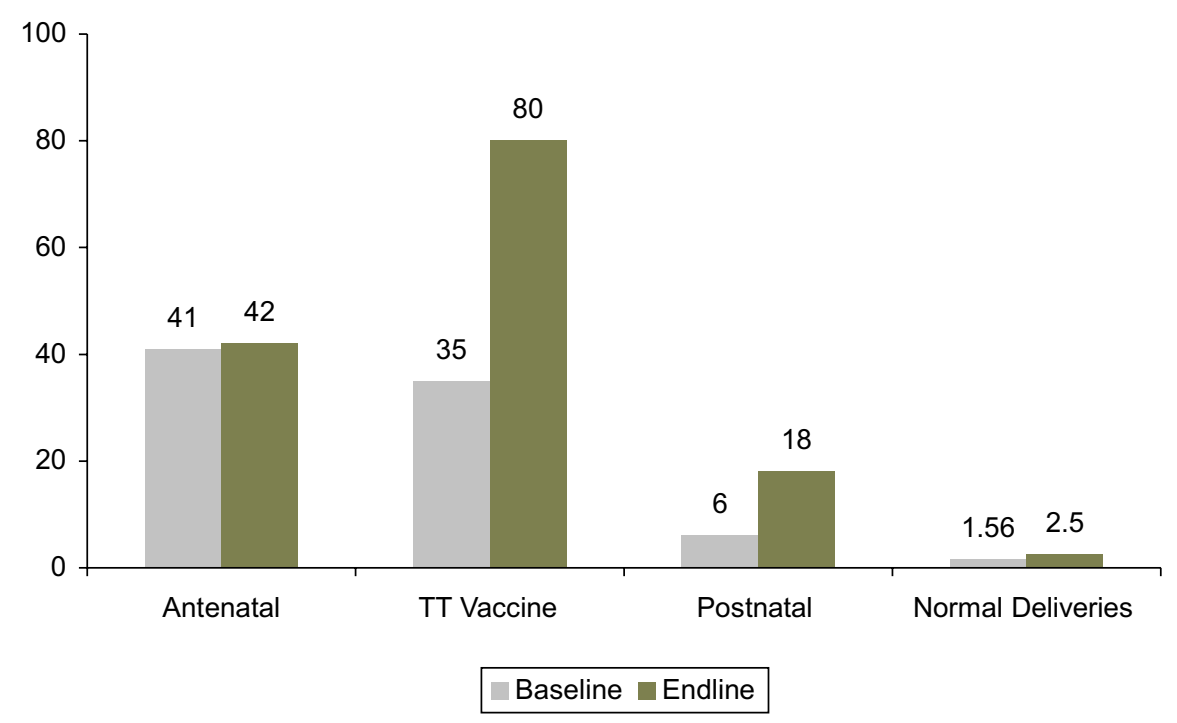

\section{Discussion}

The overall trend of health services shows a slight improvement with regard to supplies, staffing and client load. But there are many gaps in the health services, which need to be filled to make the services ready for maternal health care. Supplies such as medicines, contraceptives, and equipment are insufficient and most of the time irregular. Although by endline, more clients were attending the OPD compared to $\mathrm{BL}$, the average number of clients was still very low. It was also observed that more clients are consulting for ANC immunization services, but very few women. By addressing these shortcomings, the health system can be made more responsive. 



\section{Behaviour of Service Providers}

\section{Introduction}

Quality of care is the degree to which health services for individuals and populations increase the likelihood of desired health outcomes and are consistent with current professional knowledge (Campbell, 1975). Quality of health care is a matter of achieving better health outcomes. The definition underlines a very important aspect of quality: its relationship to scientific knowledge about effective interventions. High quality care can be achieved when interventions that work are applied to the right patients, at the right moment and at the right place. Improving quality in health can thus be seen as a matter of finding out and defining what the best clinical practice is and of promoting evidence-based everyday practice, following such defined "best practice". Best practice can be defined in the form of evidence based clinical practice guidelines or evidence based recommendations.

Quality of care framework (Bruce, Judith 1990) describes different elements of QoC. One of the main elements is the client-provider relationship. This means that the client has the right to be welcomed at the health facility, be respected and receive polite and friendly treatment, without any prejudice. The service provider owes this behavior to his/her clients.

Under the SMART project, service providers were trained in the Client Centered Approach (CCA) training (referred to SMART Report No.2). For the SMART project, CCA training was proposed as one of the principal aims of training under the "Health Services Intervention Package". The main objective was to train the service providers (doctors and paramedics) working in government health facilities in DG Khan, in order to improve their behaviour towards their clients and to acquire interpersonal communication skills.

\section{Client-Centered Approach}

CCA is behaviour cum communication training. CCA is the way a service provider deals with the client, focusing on the client's needs. In the broader context of health care, this approach addresses all relevant health needs of the clients. The concept of CCA builds on the behaviour and communication skills of the service provider. CCA aims to give clients a friendly welcome and appropriate care in a respectful way, so that the client expresses his/her needs and situation in a free and confident manner. This requires a change in the behaviour of service providers and a shift in the manner service providers often deal with their clients. It also demands that service providers equip themselves with interpersonal communication skills. 
During the baseline health services assessment, client provider interactions were observed by the research team at the visited facilities. A team member sat in the consultation room with the consent of the provider and the client and filled the observation guide. In the endline HSA, after two years, observations were again carried out to see the effect of training on the provider's behaviour towards the client. The observation guide was structured according to the checklist that comes as the final tool during CCA training. This list divides the consultation process between a client and provider into four steps:

\section{Step 1: Salutation}

This is the part of consultation when the client enters the consultation room. The providers are expected to welcome the client in a friendly manner; be polite and respectful towards him/her; ensure privacy and assure the client of confidentiality.

\section{Step 2: Assessment}

This step comprises all the activities and actions performed by the provider to diagnose the problem/s of the client, with all possible contextual details. This includes asking open-ended questions, avoiding close-ended questions, taking permission for examination, explaining the reasons for and results of the examination, exhibiting positive behaviour and avoiding both aggressive and passive behaviour. It emphasizes the use the tools of interpersonal communication. It also includes addressing the other $\mathrm{RH} /$ health needs of the client, apart from the most pressing need for which the client comes for consultation, as well as asking the client about his/her intentions pertaining to his/her heath/RH needs.

\section{Step 3: Help}

This is the part where service provider helps the client to address his/her RH/health needs. A process of negotiation rather than motivation is emphasized in CCA, by giving more options to the client to solve his/her problem/s. An important feature of negotiations is that one can always re-visit and re-negotiate, if one solution does not work. In case a client is to be referred to another facility for management, he/she must be given full referral information regarding time, cost, location, transport, facilities and availability of the provider and services.

\section{Step 4: Reassurance}

This is the last part of the interaction, where the provider asks the client to repeat the instructions and ensures the client of his/her availability. This reassures the client as well as the provider that they have understood each other correctly.

These four steps are the basis of an acronym, "SAHR". Client provider interaction observations were carried out according to the SAHR checklist, which is the essence of the CCA. 
During baseline HSA, a total number of 202 client-provider (CP) interactions were observed, whereas in the endline survey, 133 interactions were observed. The number of observations varied with each service provider, ranging from one to six (on average four observations of each service provider were conducted). The following table shows the number of observations carried out at baseline and endline to record the behaviour of the service provider before and after intervention. The data presented in this chapter is extracted from these observations.

\section{Table 4.1: Total number of observation of service providers in both rounds}

\begin{tabular}{lrr}
\hline Indicator & Baseline & Endline \\
\hline Observations & 202 & 133 \\
Total & $\mathbf{2 0 2}$ & $\mathbf{1 3 3}$ \\
\hline
\end{tabular}

\section{Characteristics of Service Providers}

During the baseline observations of client-provider (CP) interactions, an almost equal number of observations were carried out for males and females, i.e., 106 (53\%) of these observations were carried out with male service providers, while 96 (47\%) were with female service providers. During the endline survey, slightly more observations (59\%) were done with male service providers as compared to less (41\%) with female service providers.

During the baseline, the majority of $\mathrm{CP}$ interaction observations were of male doctors (38\%), followed by female paramedics (30\%), female doctors $(18 \%)$, and male paramedics $(14 \%)$ respectively. The situation was slightly different during the endline survey, where the maximum observations were made when a client presented to a female doctor $(42 \%)$, followed by observations of male doctors (33\%), female paramedics $(17 \%)$ and male paramedics $(8 \%)$.

The majority of interactions at baseline were observed at BHUs, followed by RHCs, DHQ, and THQ hospitals respectively in both rounds. The proportions of observations were decreased for BHUs and increased for other types of facilities during the endline survey. 
Table 4.2: General characteristics of service providers for the observations during both rounds of HSA

\begin{tabular}{|c|c|c|c|c|}
\hline \multirow[b]{2}{*}{ Characteristics } & \multicolumn{2}{|c|}{ Baseline } & \multicolumn{2}{|c|}{ Endline } \\
\hline & $\mathbf{N}$ & $\%$ & $\mathbf{N}$ & $\%$ \\
\hline \multicolumn{5}{|l|}{ Sex of service provider } \\
\hline Male & 106 & 52.5 & 55 & 41.4 \\
\hline Female & 96 & 47.5 & 78 & 58.6 \\
\hline \multicolumn{5}{|c|}{ Designation of service provider } \\
\hline SMO & 17 & 8.4 & & \\
\hline WMO & 36 & 17.8 & 56 & 42.1 \\
\hline MO & 60 & 29.7 & 41 & 30.8 \\
\hline FMTIFHT & 3 & 1.5 & 4 & 3.0 \\
\hline MTVHT & 13 & 6.4 & 7 & 5.3 \\
\hline Midwife & 8 & 4.0 & 2 & 1.5 \\
\hline Dispenser & 16 & 7.9 & 4 & 3.0 \\
\hline LHV & 49 & 24.3 & 16 & 12.0 \\
\hline Medical assistant & & & 3 & 2.3 \\
\hline \multicolumn{5}{|c|}{ Profession of service provider by sex } \\
\hline Male doctors & 77 & 38.1 & 44 & 33.1 \\
\hline Female doctors & 36 & 17.8 & 56 & 42.1 \\
\hline Male paramedics & 29 & 14.4 & 11 & 8.3 \\
\hline Female paramedics & 60 & 29.7 & 22 & 16.5 \\
\hline \multicolumn{5}{|l|}{ Type of facility } \\
\hline $\mathrm{DHQ}$ & 13 & 6.4 & 17 & 12.8 \\
\hline THQ & 10 & 5.0 & 12 & 9.0 \\
\hline $\mathrm{RHC}$ & 52 & 25.7 & 43 & 32.3 \\
\hline $\mathrm{BHU}$ & 122 & 60.4 & 61 & 45.9 \\
\hline Civil Hospital & 5 & 2.5 & & \\
\hline Number of respondents & 202 & 100.0 & 133 & 100.0 \\
\hline
\end{tabular}

\section{Results}

The overall results show an improvement in the behaviour of service providers towards their clients, although not to the extent that was expected. If we analyze the four steps of SAHR, the following were the results of client provider observation for each step:

\section{Salutation}

As mentioned earlier, this is the first part of interaction between the client and the service provider. It is expected that the client will receive a warm and friendly welcome from the service provider. The service provider ought to ask the client to sit down. He/she should create a relaxed atmosphere by inquiring about the general wellbeing of the client and ask some icebreaking questions, just make the client relax and to create a friendly atmosphere. 


\section{Figure 4.1: Percentage of service providers following norms of salutation}

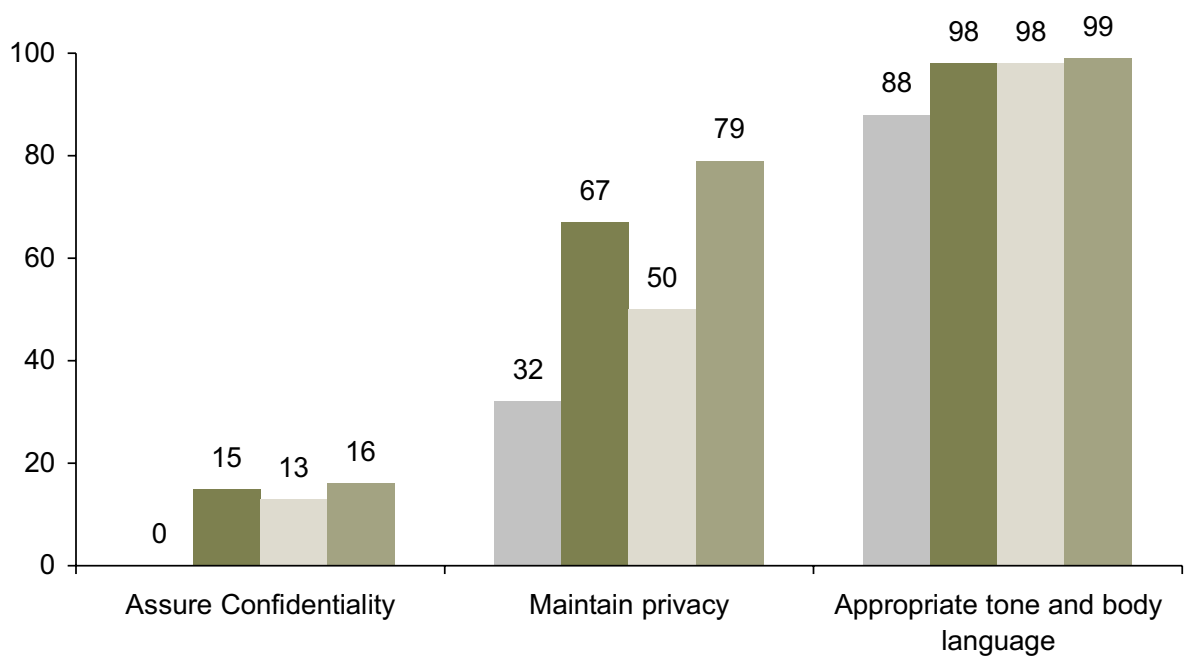

Baseline(All) $\square$ Endline(All) $\backsim$ Untrained $\square$ Trained

Privacy is an important prerequisite for a client-provider interaction, especially for clients with reproductive health problems. Privacy can be maintained if the clients are called for consultation one by one and, at the time of consultation, no one else is listening to the conversation between the service provider and the client. In this way, the client feels relaxed and expresses her/his situation comprehensively. During the majority of interactions, service providers did maintain the privacy of the client at endline compared to baseline interactions, when privacy was maintained only during one third of CP interactions. Results also show that, after training, some service providers were assuring the client that all the discussion would be kept confidential. No service provider was doing so at baseline. Privacy and confidentiality are extremely important in breaking the barriers of communication and allowing the client to express her/his situation without any hesitation or fear.

Although the overall analysis of all service providers at baseline and at endline showed marked improvement in several indicators, it is interesting to compare separately, at endline, those who were untrained and those who were trained in CCA. Some indicators showed an improvement in both groups, while some important indicators reflected a more pronounced improvement in those only who was trained. For example, during fifty percent of the observations, the untrained maintained privacy during the client provider consultation, compared to almost 80 percent of the observations of those who were trained. Proportionately more trained service providers were assuring the client regarding confidentiality of the discussion and were using the appropriate tone and body language, compared to untrained service providers but the percentage difference is not as high. 


\section{Assessment}

Assessment is the part of discussion when service provider assesses the client's problem and situation in the light of all contextual information. Most of the indicators of a good assessment have shown improvement. It is important to assess the immediate and most pressing needs of the client, besides assessing other RH needs. For example, if a client comes for consultation because her infant child has diaorrhea, there could be other needs of this client. She may have other children less than five years, who need vaccination, or they must have regular growth monitoring, or she may be pregnant or wanting to delay her next pregnancy, etc. This interaction provides an excellent opportunity to address those needs as well.

Results show that service providers now are assessing other $\mathrm{RH}$ needs of the clients during a third of observations.

Figure 4.2: Percentage of service providers assessing the RH needs and intentions of clients

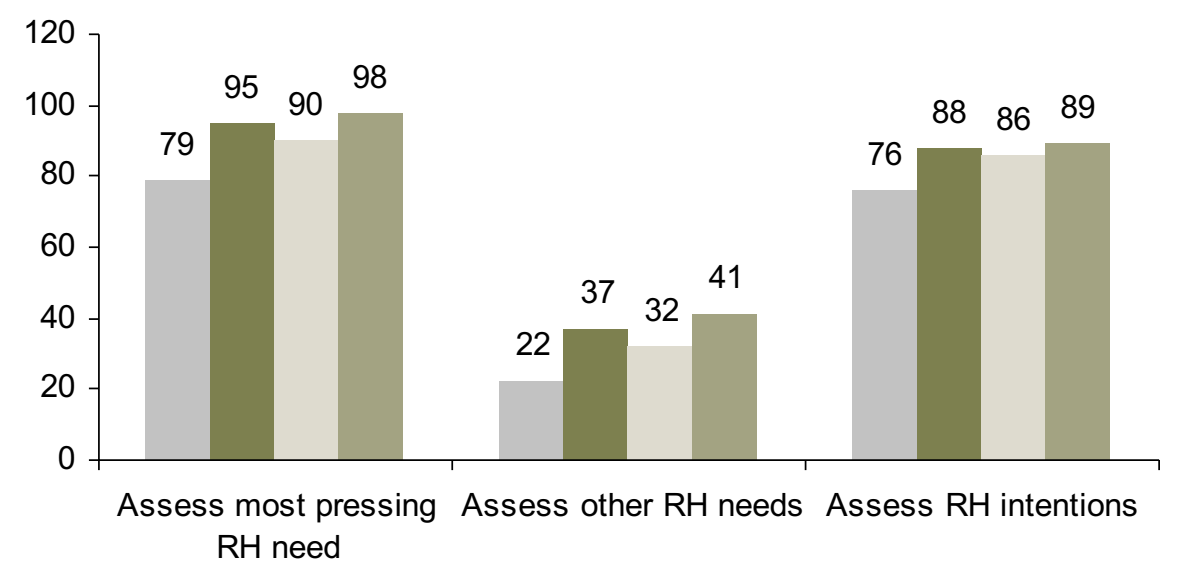

Base line(All) $\square$ End Line(All) $\square$ Untrained $\square$ Trained

During the majority of observations, service providers did inform the client about the results of the physical examination, whereas at baseline in one-third of interactions they did so. It is important to explore the pre-existing knowledge of the client about the problem and issues to reach a correct diagnosis of the problem and to help the client accordingly. Service providers were using this practice during almost 40 percent of interactions, compared to only 13 percent at baseline. 


\section{Figure 4.3: Percentage of service providers using communication tools during client-} provider interaction



Some specific tools of communication such as "reflective listening", "Stroking" and "Ownership" had been adopted and practiced by the service providers. ${ }^{6}$ Other indicators of positive behaviour of the service provider have also shown improvement at endline.

For assessing the situation of the clients, asking questions is the basic communication skill. Generally, open-ended questions should be asked in a non suggestive way and where appropriate, indirect rather than direct questions should be asked to collect information on sensitive issues. Overall results show an improvement towards the endline in the way service providers ask questions. Additionally, questions to probe the pre existing knowledge of the client about an issue and to determine underlying attitudes/health beliefs were more frequently asked by the service providers at endline. Trained service providers showed more change in a positive direction compared to untrained service providers, although the improvement was also observed in untrained service providers for some of the indicators.

${ }^{6}$ Reflective Listening: To reflect back the words and feeling of the client in a way that the client feels that her message and emotions have been understood by the service providers.

Stroking: Appreciating the client during interaction; bucking up.

Ownership: Sincere decision-making on the part of the service provider, regarding the roles and responsibilities and extent for a particular problem.

"I" Statement: After setting the "ownership of the problem", giving a sincere and clear statement to the client without any prejudice or aggressiveness. 


\section{Help}

Help is the part of the interaction when the problem/s of the client have been diagnosed and assessed with all contextual facts and the service provider now offers remedial measures for solving the problem. This part constitutes a dialogue and negotiations between the client and the service provider.

Traditionally, service providers are more inclined towards helping the client and giving them prescriptions without considering the specific circumstances of the client or the feasibility of usage and compliance of the treatment. SAHR approach emphasizes negotiating the solution with the client and giving relevant information regarding the availability, dosage, duration, and follow up mechanisms of the treatment. Results show an improvement in information exchange to empower the clients, but the negotiation part has not shown a substantial improvement towards endline. At endline, more service providers were also involving the accompanying family member in the process of discussion, something that was missing during the baseline observations.

In case a service is not available at a facility, the client must be referred to an appropriate facility with all relevant referral information, e.g. location, distance, transport, cost, timings and availability of service provider at the referred facility. During the endline observation, more clients were referred to other hospitals compared to at baseline. The majority of the referred clients at endline were also given relevant referral information. Trained service providers showed a marked positive difference in this regard compared to untrained ones.

Figure 4.4: Percentage of service providers providing help and guidance to the clients



Base line $\square$ Endline (All) $\backsim$ Untrained $\square$ Trained 


\section{Reassurance}

"Reassurance" is the last part of the client provider interaction and both client and service provider needs assurance. The service provider wants to know whether the client has understood clearly what has been discussed during the consultation and that he/she would adopt and continue the treatment. The client needs to be reassured that the problem will be resolved and feel that all his/her fears have been allayed. Endline data shows that during one third of interactions, service providers reassured the client and allayed her fears regarding the problem, while at baseline, during only one-fifth of interactions, providers were doing so. In addition, more service providers provided support and encouragement to the client at the end line compared to baseline. It is important to mention specifically when the client has to return for the follow-up visit. Endline data shows that during half of the observations, clients were told when to return for a follow up, compared to one third of such observations at baseline (For detailed tables see Annex 4- Behaviour of service providers).

\section{Discussion}

Overall results show that the CCA training was well received by the service providers in DG Khan. Several indicators of behaviour change towards the client were observed and service providers were generally applying the SAHR concept in their clinical practice.

Beside the overall effectiveness of the training, some important indicators have shown little or no improvement. This suggests that the follow-up refresher training of the service providers is vital to avoid a waning effect. It is important to note that the there was a gap of more than two years between the training and the endline survey. Moreover, there is little difference regarding some of the indicators between those who were trained in CCA and those who were not. . This points to the need for greater efforts regarding the measurement of complex indicators such as behaviour change, which is qualitative in nature, with a better design. Some of the intended behaviour had shown very little or no change. This needs to be seen in the cultural and historical context and innovative ways to improve certain training contents should be sought. Training of supervisors and inclusion of behaviour indicators in the supervisory checklist will also ensure the continuity of SAHR practice by service providers

CCA training has shown positive results and is worth replicating in the safe motherhood programmes. A follow up refresher, however, is necessary to maintain the dynamics of the practice and application of CCA. 



\section{Perceptions of Clients Regarding Service Providers}

\section{Introduction}

Client exit interviews were also carried out to get the client's perspective of the quality of the care they received from the service provider. Client exit interviews were carried out with clients coming to the health facility seeking health care (facility-based client exit interviews).

Interviews were also carried out with the women at their homes (in the neighbourhood of the facility), who had visited the facility for health care within the previous three months. The results of these interviews have also been discussed in this chapter to support the analysis.

Table 5.1: Number of interviews conducted with women at the facility and at home (both rounds)

\begin{tabular}{lrr}
\hline Client Interviews & Baseline & Endline \\
\hline Facility-based exit & 248 & 235 \\
Community-based exit & 320 & 244 \\
Total & 568 & $\mathbf{4 7 9}$ \\
\hline
\end{tabular}

During the Health Services Assessment, exit interviews were carried out with women who came to the facility on that particular day. A total number of 483 women were interviewed, 248 during baseline and 235 during the endline survey. Most of these interviews were conducted at BHUs, followed by RHCs, DHQ and THQ hospitals during both rounds. Proportionally more interviews were conducted at DHQ and THQ hospitals during endline compared to baseline. This was due to the fact that number of DHQ, THQ and RHCs visited during both rounds remained the same. However the number of sampled BHUs was reduced from 35 to 20 at EL due to financial constraints.

Most of the women interviewed in the facility during both rounds were between 20 and 29 years of age (44\% in both rounds), while more than one third were between 30 and 39 years old (35\% in baseline and $40 \%$ in endline survey). Almost 7 percent of the women were less than 20 years old in both rounds.

We also did exit interviews with women of the community who had visited the facility for consultation within the previous three months. A total of 564 women were interviewed in the community; 320 women were interviewed during baseline assessment and 244 at endline. 
Table 5.2: Characteristics of respondents

\begin{tabular}{|c|c|c|c|c|c|c|c|c|}
\hline \multirow[b]{3}{*}{ Characteristics } & \multicolumn{4}{|c|}{ Facility-based exit } & \multicolumn{4}{|c|}{ Community- based exit } \\
\hline & \multicolumn{2}{|c|}{ Baseline } & \multicolumn{2}{|c|}{ Endline } & \multicolumn{2}{|c|}{ Baseline } & \multicolumn{2}{|c|}{ Endline } \\
\hline & $\mathrm{N}$ & $\%$ & $\mathrm{~N}$ & $\%$ & $\mathrm{~N}$ & $\%$ & $\mathrm{~N}$ & $\%$ \\
\hline \multicolumn{9}{|l|}{ Age of the client } \\
\hline Less than $20 \mathrm{yrs}$ & 18 & 7.3 & 16 & 6.8 & 17 & 5.4 & 14 & 5.7 \\
\hline $20-29$ yrs & 110 & 44.5 & 104 & 44.3 & 132 & 41.6 & 108 & 44.3 \\
\hline $30-39$ yrs & 86 & 34.8 & 94 & 40.0 & 124 & 39.1 & 98 & 40.2 \\
\hline $40 /+y r s$ & 33 & 13.4 & 21 & 8.9 & 44 & 13.9 & 24 & 9.8 \\
\hline \multicolumn{9}{|c|}{ Marital status of client / respondent } \\
\hline Currently married & 234 & 94.7 & 232 & 98.7 & 306 & 96.5 & 236 & 96.7 \\
\hline Divorced & 0 & 0.0 & 1 & 0.4 & 0 & 0.0 & 0 & 0.0 \\
\hline Separated & 0 & 0.0 & 1 & 0.4 & 1 & 0.3 & 1 & 0.4 \\
\hline Widowed & 3 & 1.2 & 0 & 0.0 & 3 & 0.9 & 4 & 1.6 \\
\hline Never married & 10 & 4.0 & 1 & 0.4 & 7 & 2.2 & 3 & 1.2 \\
\hline \multicolumn{9}{|l|}{ Type of Facility } \\
\hline $\mathrm{DHQ}$ & 19 & 7.7 & 46 & 19.6 & 13 & 4.1 & 15 & 6.1 \\
\hline $\mathrm{THQ}$ & 13 & 5.2 & 30 & 12.8 & 10 & 3.1 & 16 & 6.6 \\
\hline $\mathrm{RHC}$ & 64 & 25.8 & 58 & 24.7 & 61 & 19.4 & 63 & 25.8 \\
\hline $\mathrm{BHU}$ & 151 & 61.3 & 101 & 43.0 & 225 & 70.9 & 150 & 61.5 \\
\hline Others & 0 & 0.0 & 0 & 0.0 & 8 & 2.5 & 0 & 0.0 \\
\hline Number of respondents & 247 & 100.0 & 235 & 100.0 & 317 & 100.0 & 244 & 100.0 \\
\hline
\end{tabular}

\section{Characteristics of Women}

Most of the women who were interviewed in the facility during both rounds were between 20 and 29 years of age (40\% in baseline and $44 \%$ in endline), while more than one third were between 30 and 39 years (39\% in baseline and $40 \%$ in endline survey). Almost $5 \%$ of the women were less than 20 years in both rounds.

During baseline survey, 71 percent of community women who were interviewed had been to BHUs for consultation within in the last three months; at endline, 61 percent of those interviewed had been to BHUs.

\section{Characteristics of Service Providers Consulted by Women}

Most of the facility based exit interviews (33\%) were conducted with women who were presented to a male doctor during the baseline survey; in the endline survey, most of the 
interviews (35\%) included women presenting to a female doctor. A reasonable proportion (27\%) presented to an LHV during baseline, compared to only 14 percent at endline.

Most of the community based exit interviews (35\%) were conducted with the women who were presented to a male doctor during the baseline survey, compared to the endline survey when most of the interviews (40\%) included women presenting to a male doctor. A reasonable proportion (29\%) presented to an LHV during baseline, compared to only 23 percent at endline.

Figure 5.1: Designation of service providers consulted by women during the facilitybased exit

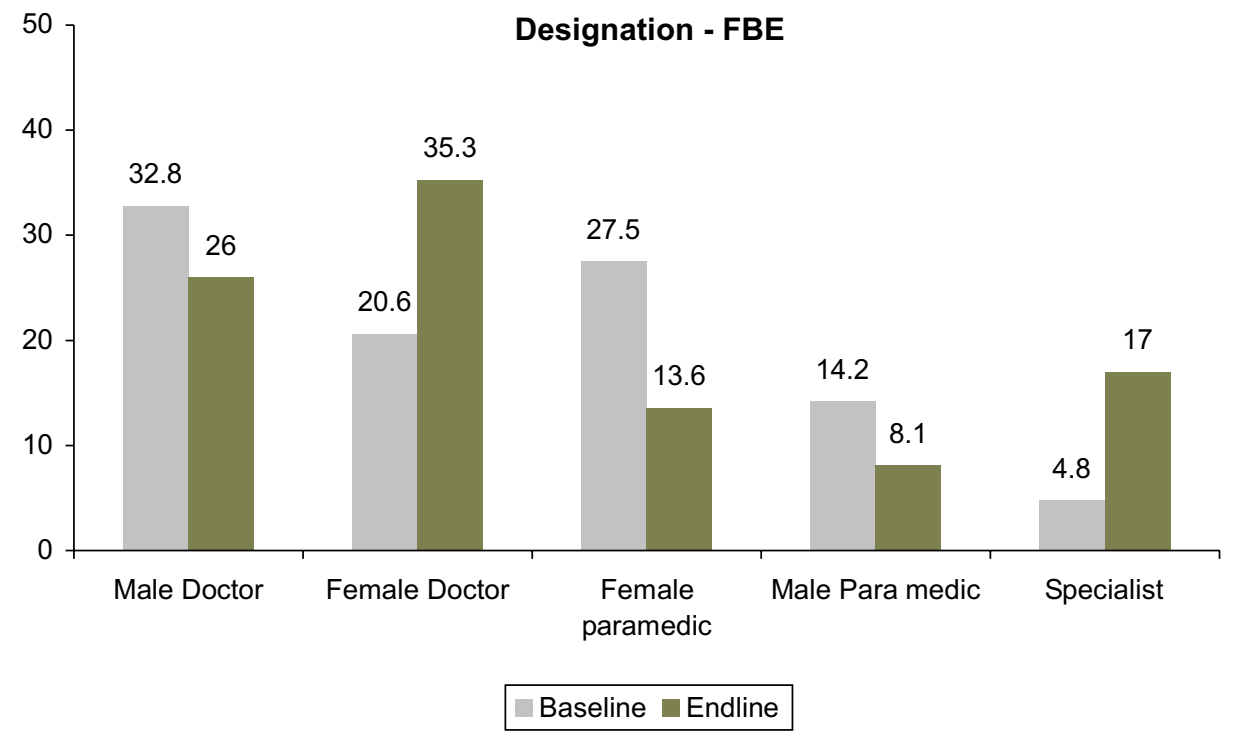

\section{Purpose of Visit}

Most of the facility based exit interviews in the baseline survey were conducted with women who came to the facility for the purpose of infant/child health, followed by women who came for general illness, ANC, FP and post natal care respectively. Compared to this, in the endline survey, most interviews were carried out with women who came for general illness, followed by ANC, infant/child care, FP and postnatal care. 
Figure 5.2: Designation of service providers consulted by the women during facilitybased exit

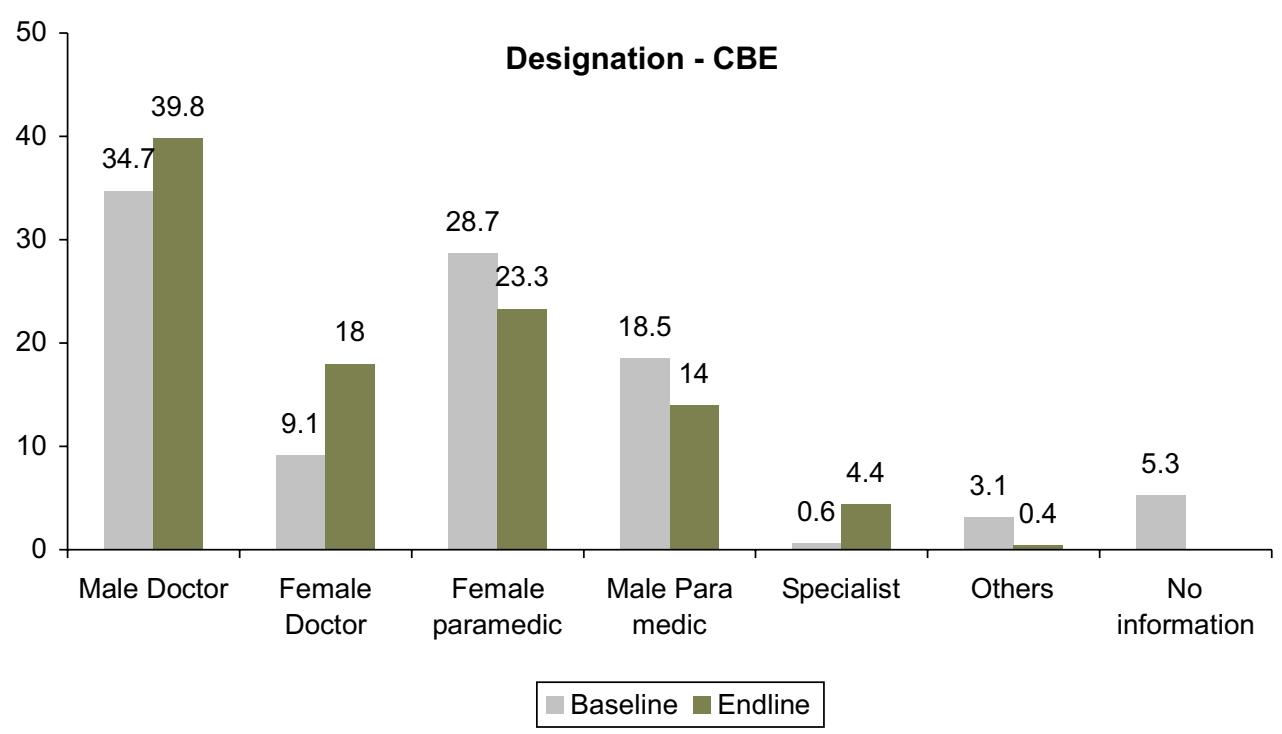

Almost the same situation is seen in the interviews conducted with community women. Most of the community-based exit interviews were conducted with the women at the baseline survey who visited the facility for the purpose of infant/child health, followed by women who came for general illness, ANC, FP and post natal care respectively. Compared to this, at the endline survey, most interviews were carried out with the women who came for general illness, followed by infant/child care, ANC, FP and postnatal care.

Figure 5.3: Distribution of respondents by purpose of visit. Facility based exit at $B L$ and EL

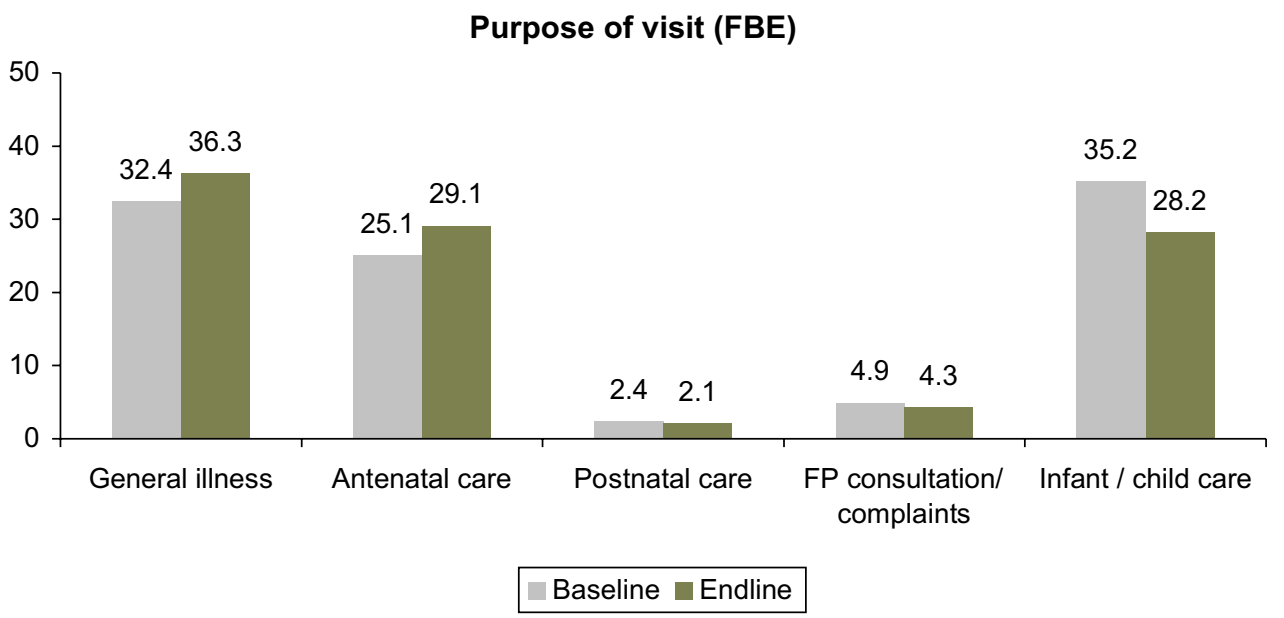


Figure 5.4: Distribution of respondents by purpose of visit. Community based exit at BL and EL

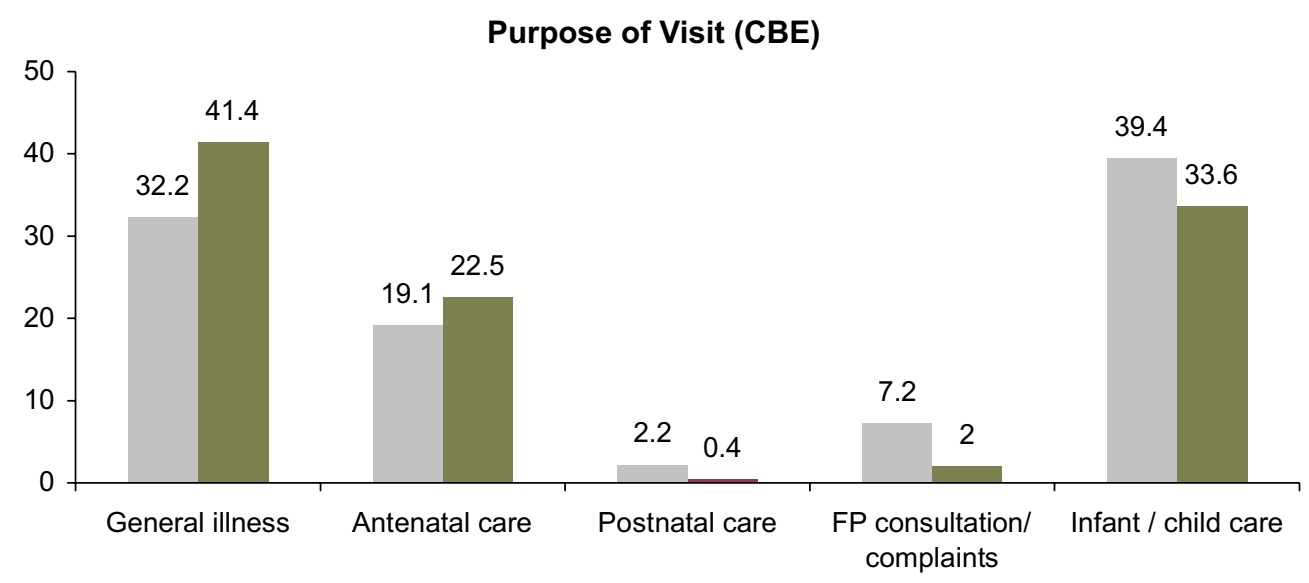

Baseline $\square$ Endline

\section{Results}

The majority of women who were interviewed at the health facilities or at home responded positively towards the service provider and the services they received. Their perceptions had shown an improvement in the behaviour and technical knowledge of the service provider when we compared BL and EL interventions. There was no substantial difference between perceptions of women at the facility and those at home.

Following are the results of data collected from women who came to the facility for consultation on the day of the PC team visited and from the women who had visited the same facility within the previous three months.

\section{Perceptions regarding assessment of clients}

\section{Opportunity for the client to explain}

Women who came to the facility for consultation were asked whether the service provider gave them an opportunity to explain their problem. At baseline, 93 percent of women responded positively, saying that the provider gave them the opportunity to explain their complaints. 98 percent of women at endline thought the provider gave them an opportunity to explain their problem. The women of the community were asked the same question. At baseline, 97 percent women responded positively, saying that the provider gave them ample opportunity to explain. 99 percent of women at endline thought that the provider gave them an opportunity to explain their problem. 
Figure 5.5: Perceptions of clients regarding assessment skills of the service providers (FBE)

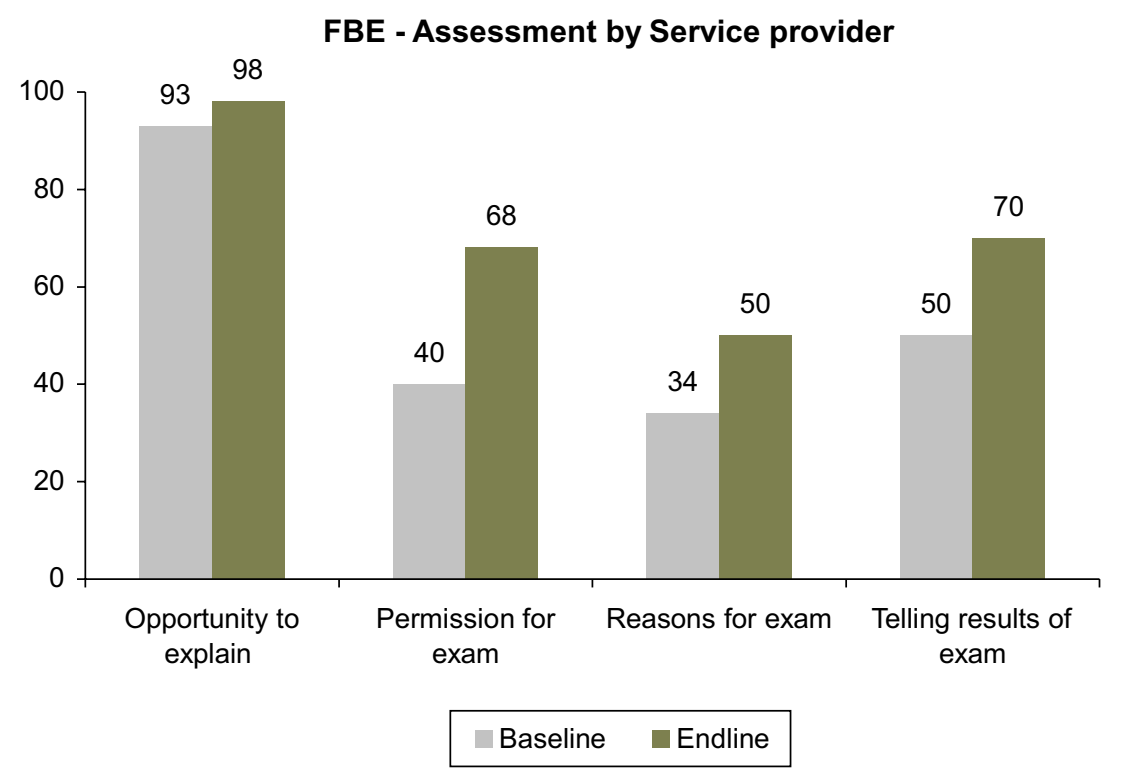

Figure 5.6: Perceptions of clients regarding assessment skills of the service providers (CBE)

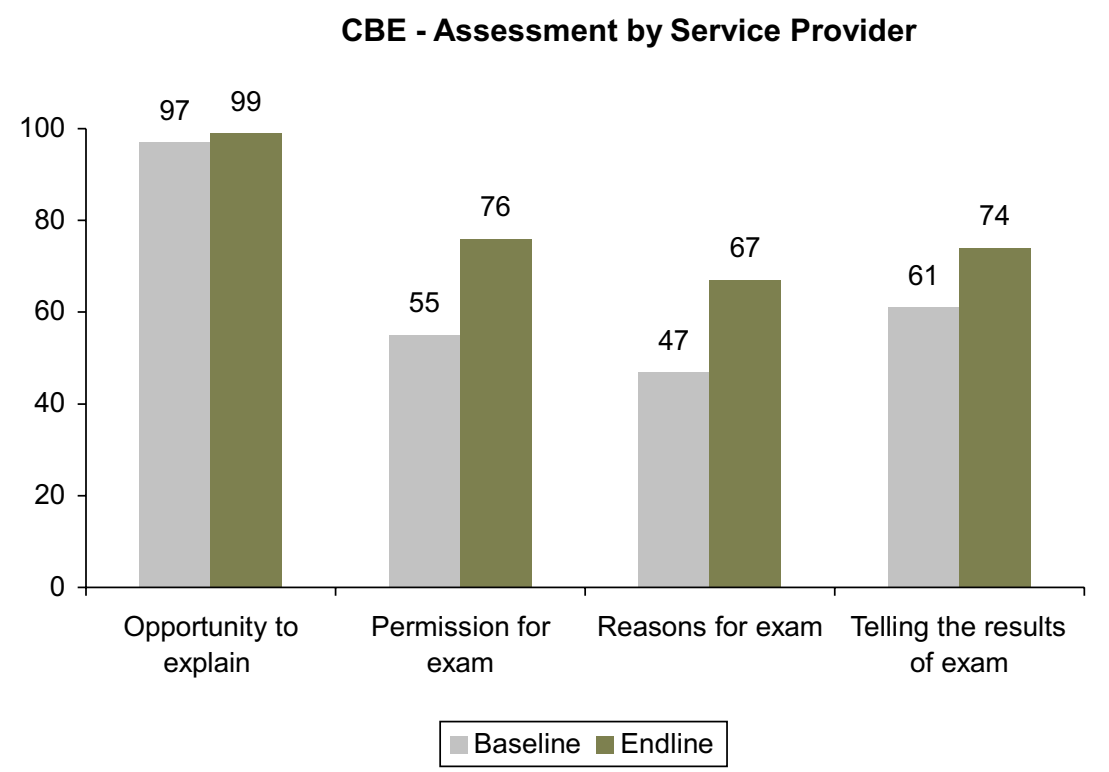

\section{Permission for examination}

Examination is an important part of assessment and permission should be taken before conducting any type of examination, even if it is something simple, such as checking blood 
pressure, temperature, pulse counting or throat examination. Almost 40 percent of the clients who visited the facility at baseline responded that the service provider did ask for permission before conducting an examination; at endline 68 percent of clients said that the service providers seek permission for examination. There is a prominent increase in this indicator. More than half $(55 \%)$ of the community women at baseline responded that the service provider did ask for permission before conducting an examination; at endline, an overwhelming number $(76 \%)$ of clients said that the service providers sought permission for examination.

\section{Reasons for examination}

Giving reasons for the examination is necessary before examination. Nearly one third of the women who came for consultation to the facility responded at baseline that the provider explained why the examination was performed. When we compared this to endline data, an increase was observed. Now fifty percent of the women responded that the service provider explained the reasons for carrying out the examination. We asked the women in the community the same question; nearly half $(47 \%)$ of them responded at baseline that the service provider explained the reasons for the examination to them. When we compared baseline data to endline, the data showed an increase in this indicator. Now, two thirds of the women responded positively.

\section{Telling Clients Results of Examinations}

During the training of service providers, it was emphasized that telling the results of any examination is vital for the client's satisfaction and improvement of quality of care. 50 percent of the women who came to the facility at baseline responded that they were told about the findings of the examination. At endline, this number had increased to 70 percent. At baseline, more than 60 percent of the women in the community responded positively. At endline, this number had increased to 85 percent. This shows that the service providers were applying the concepts of training in their clinical practice.

\section{Referral and referral information}

During baseline assessment three percent of women who came to a facility responded that the service providers did refer them when needed. Endline data shows an increase in this indicator. Now six percent of women responded that the service providers were referring them. This percentage showed an even greater increase in interviews conducted with the women in the community. At baseline, only two percent of women in the community had responded positively, while at endline, six percent women responded that service providers were referring them. 
Table 5.3: Perceptions of service providers regarding referral information received by the service provider (facility based exit interviews and community based exit interviews)

\begin{tabular}{lrrrr}
\hline & \multicolumn{2}{c}{ Facility-Based Exit } & \multicolumn{2}{c}{ Community-Based Exit } \\
\cline { 2 - 5 } & Baseline & Endline & Baseline & Endline \\
\cline { 2 - 5 } Indicator & $\%$ & $\%$ & $\%$ & $\%$ \\
\hline Did the service provider refer you? & 3.0 & 6.0 & 2.0 & 6.0 \\
$\begin{array}{l}\text { Did the provider mention other places } \\
\text { where you can go for consultation? }\end{array}$ & 4.0 & 6.0 & 5.0 & 4.0 \\
$\begin{array}{l}\text { Did the provider mention when to return } \\
\text { for follow-up? }\end{array}$ & 55.0 & 66.0 & 53.0 & 63.0 \\
\hline
\end{tabular}

At the time of baseline, only four percent women who came to the facility responded that the providers mentioned other places where they could go for consultation. During endline assessment, six percent of women responded that service providers mentioned other places where they could go for consultation.

\section{Clients' perceptions regarding reassurance}

\section{Reassurance to the client for follow-up visit}

Half of the women who were interviewed at the facility and at home responded at the time of baseline assessment that service providers did mention when they should return for follow up. At EL, this proportion increased to 66 percent for facility based interviews and to 63 percent for community based interviews. Reassurance by the service provider has also shown some improvement.

\section{Recommend/Advise someone to come to that facility}

At the time of the baseline survey, 85 percent of women in the community were satisfied with services and said that they would recommend other people to come to that particular facility. At EL, 90 percent of women said that they would recommend this facility to other people.

\section{Technical knowledge of service providers}

During interviews at the facilities, the clients were asked questions regarding the process they underwent during their interaction with the service providers. These questions elaborate the technical competence of the service provider and we have separated the questions relating to different steps of an interaction and for different client needs. As these clients were broadly divided into four types, depending on the purpose of their visit, technical competencies can be viewed differently for these clients. 


\section{Asking questions to assess client's situation}

A detailed history taking is the hallmark of any client provider interaction. Relevant questions regarding the specific case and condition help the service provider understand the client's situation in a comprehensive manner. Women who came to the facility for consultation were asked what the service provider asked them to assess their situation.

\section{Safe motherhood}

More providers at the EL were asking about the duration of illness, past obstetrical history and number of children. At baseline assessment, only nine percent women said that the service provider had asked about the duration of the illness, while at EL, twenty six percent of women (responded) positively to the same question. During baseline assessment, none of the women said that the service provider asked about their past obstetric history. Endline assessment shows an improvement in this indicator to twelve percent.

\section{Table 5.4: Perceptions of clients regarding history taking skills of the service provider}

\begin{tabular}{lrrrr}
\hline What did the provider ask you to assess & \multicolumn{2}{c}{ Baseline } & \multicolumn{2}{c}{ Endline } \\
\cline { 2 - 5 } your situation? & $\mathbf{N}$ & $\%$ & $\mathbf{N}$ & $\%$ \\
\hline Safe Motherhood Clients & 7 & 9.1 & 22 & 26.2 \\
$\quad$ Duration of illness & 0 & 0.0 & 8 & 11.9 \\
$\quad$ Past obstetric history & 7 & 11.3 & 8 & 11.9 \\
$\quad$ Past medical history & 8 & 12.9 & 10 & 14.9 \\
$\quad$ Number of living children & & & & \\
Family Planning Clients & 0 & 0.0 & 2 & 22.2 \\
$\quad$ Problem(s) with method & 1 & 10.0 & 1 & 11.1 \\
$\quad$ Pains or cramps in legs & 0 & 0.0 & 1 & 11.1 \\
$\quad$ History of diabetes & & & & \\
Child Health & 1 & 1.3 & 11 & 16.2 \\
$\quad$ What the problem is & 5 & 6.3 & 14 & 20.6 \\
$\quad$ Duration of illness & 1 & 1.3 & 1 & 1.5 \\
$\quad$ Breastfeeding & &
\end{tabular}




\section{Family Planning}

At EL, more women perceived that service providers were dealing with the problems of contraceptives. At the baseline survey, not a single woman responded that the service provider had asked about any problem with FP methods. At EL, however, twenty two percent of women responded that the service provider had asked about problems with FP methods. Data shows that at EL, more service providers were asking about the history of diabetes during consultations with FP clients.

\section{Child Health}

Towards the EL, more service providers were asking questions related to problems of children and the duration of an illness.

\section{Physical Examination of Clients}

A careful general physical and systemic examination is necessary to diagnose the problem of the client. Overall perceptions of women regarding the physical examination performed by the service providers during consultation reveal that more service providers were performing examinations (e.g. general physical examination, pelvic examination, temperature and BP measurements) at EL compared to BL.

\section{Table 5.5: Perceptions of clients regard ing examination skills of the service provider (FBE interviews)}

\begin{tabular}{lcccr}
\hline $\begin{array}{l}\text { What examination did the provider } \\
\text { perform? }\end{array}$ & \multicolumn{2}{c}{ Baseline } & \multicolumn{2}{c}{ Endline } \\
\cline { 2 - 5 } & $\mathrm{N}$ & $\%$ & $\mathrm{~N}$ & $\%$ \\
\hline General IlIness & 5 & 9.6 & 4 & 13.3 \\
$\quad$ Checked throat & 9 & 17.3 & 6 & 20.0 \\
$\quad$ Checked eyes & 0 & 0.0 & 3 & 10.0 \\
$\quad$ Checked ear & 0 & 0.0 & 2 & 6.7 \\
$\quad$ Checked blood pressure & & & & \\
Safe motherhood & 43 & 81.1 & 39 & 88.6 \\
$\quad$ Performed abdominal examination & 0 & 0.0 & 6 & 20.0 \\
$\quad$ Pelvic examination & & & & \\
Child Health & 11 & 18.0 & 17 & 40.5 \\
$\quad$ Checked temperature & 0 & 0.0 & 3 & 7.1 \\
$\quad$ Checked for boils & & & & \\
\hline
\end{tabular}




\section{Information given to the clients}

When a service provider makes a provisional or definite diagnosis regarding a client's problem, helping the client through giving relevant technical information empowers the client. When women were asked what information they received from the service provider during their consultation, more women at EL thought that they were receiving information regarding nutrition, TT immunization, ANC and the importance of delivery by a killed Birth Attendant. Women also perceived that they got information about the usage, effectiveness and possible side effects of FP methods.

Results show similar trends of behavior change among the service providers according to both sets of respondents i.e. interviewed at home and at clinic.

Table 5.6: Perceptions of clients rega rding information given by the service provider

\begin{tabular}{lrrrr}
\hline What information did you get from the & \multicolumn{2}{c}{ Baseline } & \multicolumn{2}{c}{ Endline } \\
\cline { 2 - 5 } provider? & $\mathrm{N}$ & $\%$ & $\mathrm{~N}$ & $\%$ \\
\hline $\begin{array}{l}\text { General Health } \\
\quad \text { Told about follow-up }\end{array}$ & 5 & 6.5 & 23 & 27.1 \\
$\quad$ Test & 0 & 0.0 & 10 & 11.8 \\
$\quad$ Advised on taking medicines regularly & 0 & 0.0 & 5 & 5.9 \\
$\quad$ Safe Motherhood & & & & \\
$\quad$ Nutritional advice & 18 & 26.9 & 22 & 30.6 \\
$\quad$ Advice and explanation of TT immunization & 14 & 20.9 & 26 & 36.1 \\
$\quad \begin{array}{l}\text { and its schedule } \\
\text { Explained the importance of having at least }\end{array}$ & 1 & 1.5 & 7 & 9.7 \\
$\quad \begin{array}{l}\text { antenatal visits } \\
\text { Explained the importance of having delivery } \\
\text { by a trained person }\end{array}$ & 3 & 4.5 & 14 & 19.4 \\
Family Planning & & & & \\
$\quad$ How to use method & & & & \\
$\quad$ Effectiveness, duration & 2 & 18.2 & 4 & 44.4 \\
$\quad$ Possible side effects & 0 & 0.0 & 2 & 22.2 \\
\hline
\end{tabular}





\section{Conclusions and Recommendations}

Health Services Assessment of DG Khan reveals important information regarding the preparedness of the health delivery system for maternal and neonatal health care, the quality of care issues, especially behaviour and knowledge of the service providers.

\section{Health Delivery System}

The health delivery system of DG Khan is not yet ready to provide the full range of maternal and neonatal health care, although there have been some improvements in the system between baseline and endline survey. In such areas as availability of utilities (electricity, water, functioning toilet), privacy, separate counselling space, etc. noticeable but modest improvements took place. Availability of medicines was poor at baseline and did not improve overall, but for matters relating to maternal and neonatal health it did improve somewhat. Staffing was quite adequate at both baseline and endline; most postings were filled according to standard and most posted staffs (including physicians) were present on the day of our (unscheduled) visit. During the project period, three female doctors were appointed at the BHUs as Medical Officer Incharge. This is indeed another achievement.

Availability and utilization of services has also shown some improvements. Facility records show an increase in the overall client load and clients seeking to maternal and infant care. Immunization services are universally available and utilization has risen. There was an interesting pattern in utilization of maternal services. It seems that more women go to primary care facilities (BHU and RHC) for immunization and antenatal services, while for natal and postnatal services; they go to THQ or DHQ hospitals. This could possibly be due to some gaps at the PHC level to provide these services. Very few normal deliveries were being conducted at PHCs. Comprehensive EmOC services are only available at the DHQ hospital. No facility had a neonatal ICU. Recently, two new female doctors have been appointed at the THQ hospital and this has resulted in an increased female clientele.

On the whole, it can be said that the public health system has improved during the period of the project, but not to the degree, that could be expected to result in readiness to provide comprehensive maternal and neonatal health care. Up gradation or improvement in physical facilities was not on the objectives of the SMART project: it is for future interventions to consider the gaps in the health delivery system that have the potential to nullify other capacitybuilding efforts. Some of the focus areas in this regard for future programmes could be the infrastructure, infection prevention practices, regular and improved supply of medicines, equipment, availability of round the clock maternal and neonatal health facilities, greater 
referral linkages (within the system and with community), a supportive supervisory system, and, above all a visionary District Health Management System.

\section{Technical Knowledge of Service Providers}

The technical knowledge of service providers has shown a modest increase during the intervention. Although comparative assessment was not the prime intention of health services assessment, this exercise has provided some insight into the issues of training needs and future modeling. We asked four complex questions which we thought particularly important for MNH care, at both baseline and end line. Nearly two years after training, those trained in the SMART project had noticeably higher scores on all questions than those not trained. Interestingly, those receiving only CCA training also scored about as well as those receiving both CCA and technical training (because each of the four question topics was discussed in some detail during CCA training). It is worth mentioning that more than half of the intended service providers could not be trained. Most of those trained were paramedics and appointed at the PHCs. Because the EL sample of BHUs was reduced and only service providers present on the day of the visit were assessed, quite a number of trained service providers could not be assessed for technical knowledge. The training package for basic EmONC training included basic skills development and hands on training, but skills assessment was not a part of the assessment. Despite these constraints, trained service providers were found to be more knowledgeable compared to untrained providers. In order to get a more pronounced and sustained impact of training, it is strongly suggested that some mechanism of regular refresher training be instituted for all cadres of service providers.

\section{Behaviour of Service Providers}

The CCA training brought about a positive change in the behaviour of service providers to a varying extent, although not to the extent that was expected. Most of the indicators for "assessing the client's problem and situation" have shown improvement. This is by far the most important component during a client provider consultation. Traditionally, a comprehensive assessment of client needs is neglected by service providers. There is more emphasis on "helping and telling" the client, rather than "listening" to the client. CCA training was able to improve the assessment component but the negotiation part was not absorbed so well by the service providers. The general behaviour of service providers, such as politeness, respect, friendly behaviour, and care had improved.

The impact, however, was modest. There were two important reasons for this moderate outcome. Firstly, there was a gap of two years between CCA training and EL behaviour assessment. It was only 6 -day classroom training and no refresher training was planned thereafter. It is obvious that a one-time training, without any follow-up refresher, wanes after a gap of two years. Secondly, it was decided to build the capacity of the District Health 
Department to carry out CCA trainings. In view of special and multi dimensional aspects of this behaviour cum communication training, it was not easy to find suitable District trainers of CCA within the District Health Department for the implementation of the intended quality of behaviour change communication training. Nevertheless, CCA training has initiated some basic changes in a potential area of QoC.

The indirect evidence from client interviews has also augmented the evidence that knowledge and behaviour of service providers has improved during the project period. It was also assessed that there was a high demand from the providers for capacity building in the areas of EmONC and BCC. At the same time, other components of QoC (health delivery system) need to be improved. 

Annexes 



\section{Annex 1}

\section{Sampled Health Facilities of DGK for Baseline HSA-2004 and Endline HSA - 2006}

\section{S. No Baseline Endline}

1

2

3

4

5

6

7

8

9

10

11

12
DHQ Hospital D.G. Khan

THQ Hospital Taunsa

Civil Hospital Sakhi Sarwar

RHC Shadan Lund

RHC Shah Sadar Din

RHC Vehova

RHC Tibbi Qaisarani

RHC Choti Zaireen

RHC Kot Chutta

RHC Sarwar Wali

RHC Qadirabad

BHU Sameena

BHU Khakhi

BHU Nawan Shehar

BHU Khanpur

BHU Wadoor

BHU Kot Mubarik

BHU Thatha Gaboolan

BHU Bakhar Wah

BHU Hairo Sharqi

BHU Makwal Kalan

BHU Sokar

BHU Lakhani

BHU Kot Qaisarani

BHU Trimin

BHU Jhoke Budo
DHQ

THQ

RHC Vehova

RHC Qadirabad

RHC Sarwar Wali

RHC Tibbi Qaisarani

RHC Kot Chutta

RHC Choti Zaireen

RHC Shah Sadar Din

RHC Shaden Lund

BHU Jhoke Utra

BHU Mana Ahmdani

BHU Ghausabad

BHU Lohar Wala

BHU Ara Jafar

BHU Bakhar Wah

BHU Memoori

BHU Talpur

BHU Kot Mubarak

BHU Thatta Gaboolan

BHU Chabri Zarin

BHU Sameena

BHU Pir Adil

BHU Kot Haibet

BHU Khanpur

BHU Wadoor 


\begin{tabular}{|c|c|c|}
\hline S. No & Baseline & Endline \\
\hline 27 & BHU Raitera (Litra) & BHU Yaroo \\
\hline 28 & BHU Choti Zaireen & BHU Hagi Ghazi \\
\hline 29 & BHU Kot Mohi & BHU Sheru Jadeed \\
\hline 30 & BHU Kala & BHU Gadai \\
\hline 31 & BHU Mamoori & \\
\hline 32 & BHU Dauna & \\
\hline 33 & BHU Nari & \\
\hline 34 & BHU Taal Pur & \\
\hline 35 & BHU Sheroo Jadeed & \\
\hline 36 & BHU Basti Jaam & \\
\hline 37 & BHU Jhoke Utra & \\
\hline 38 & BHU Kot Haibat & \\
\hline 39 & BHU Yaroo Khusa & \\
\hline 40 & BHU Lohar Wala & \\
\hline 41 & BHU Gadaie & \\
\hline 42 & BHU Aali Wala & \\
\hline 43 & BHU Ghausabad & \\
\hline 44 & BHU Mana Ahmadani & \\
\hline 45 & BHU Aara Jafer & \\
\hline 46 & BHU Haji Ghazi & \\
\hline
\end{tabular}




\section{Annex 2}

\section{Team Formation for fieldwork of HSA DGK - Baseline 2004}

\begin{tabular}{cccc}
\multicolumn{2}{c}{ Team I } & & \multicolumn{2}{c}{ Team II } \\
Team Leader & Dr Jaskani & Team Leader & Dr Farhaj \\
PC Social Scientist & Wajahat Raza & PC Social Scientist & Saima Pervaiz \\
PC Social Scientist & Bushra Bano & Interviewer 1 & Asifa \\
Interviewer 1 & Samreen & Interviewer 2 & Robina \\
Interviewer 2 & Hina & Interviewer 3 & Sumaira \\
\hline
\end{tabular}

\section{Team formation for fieldwork of HSA DGK - Endline 2006}

\section{Supervisor: Dr Zakir Shah}

\begin{tabular}{rcc} 
Sr. No. & Team & Designation \\
1. & Dr Uzma & Medical Interviewer \\
2. & Saima Pervaiz & PC Staff \\
3. & Aasifa Jabeen & Interviewer \\
4. & Hina Samreen & Interviewer \\
5. & Saima Ashraf & Interviewer \\
6. & Rukhsana & Interviewer \\
\hline
\end{tabular}

\section{Annex 3}

Emergency Obstetric and Neonatal Care Training

\begin{tabular}{|c|c|c|}
\hline Designation & Place of Post & Venue \\
\hline Gynaecologist & DHQ, DG Khan & \multirow{4}{*}{$\begin{array}{c}\text { Pakistan Institute of } \\
\text { Medical Sciences (PIMS), } \\
\text { Islamabad }\end{array}$} \\
\hline Anesthetist & DHQ, DG Khan & \\
\hline Theatre Nurse & DHQ, DG Khan & \\
\hline Theatre Technician & DHQ, DG Khan & \\
\hline Gynaecologist & Private Practioner DG Khan & \multirow{4}{*}{$\begin{array}{c}\text { Pakistan Institute of } \\
\text { Medical Sciences (PIMS), } \\
\text { Islamabad }\end{array}$} \\
\hline Gynaecologist & Private Practioner DG Khan & \\
\hline Gynaecologist & Private Practioner Taunsa & \\
\hline Gynaecologist & Private Practioner Taunsa & \\
\hline
\end{tabular}




\section{Annex 4}

\section{Behaviour of Service Provider- Comparison of BL vs EL (All, Untrained and Trained)}

\begin{tabular}{|c|c|c|c|c|c|c|c|c|}
\hline \multicolumn{8}{|l|}{ Salutation and Assessment } & \\
\hline & $\mathrm{N}$ & $\%$ & $\mathrm{~N}$ & $\%$ & $\mathrm{~N}$ & $\%$ & $\mathrm{~N}$ & $\%$ \\
\hline \multicolumn{9}{|l|}{ Salutation } \\
\hline Greet the client in a friendly manner & 102 & 51 & 35 & 27 & 19 & 24 & 16 & 31 \\
\hline Make the client feel comfortable & 103 & 51 & 22 & 17 & 14 & 18 & 8 & 15 \\
\hline Enquire about the name of client OR call by name & 170 & 86 & 74 & 56 & 40 & 50 & 34 & 65 \\
\hline Use the opportunity to begin conversation by asking ice-breaking questions & 19 & 10 & 11 & 9 & 7 & 9 & 4 & 8 \\
\hline Try to gain the confidence to keep all her information confidential & 0 & 0 & 7 & 15 & 4 & 16 & 3 & 13 \\
\hline Maintain privacy & 44 & 32 & 34 & 67 & 23 & 79 & 11 & 50 \\
\hline \multicolumn{9}{|l|}{ Assessment } \\
\hline Observe the client & 188 & 94 & 128 & 96 & 77 & 96 & 51 & 96 \\
\hline Provide appropriate time to listen to the problem of client & 136 & 68 & 88 & 67 & 49 & 62 & 39 & 75 \\
\hline Use communication tool like "Reflective listening" & 4 & 2 & 3 & 3 & 2 & 3 & 1 & 3 \\
\hline Use communication tool like "Stroking" & 1 & 1 & 12 & 10 & 9 & 12 & 3 & 7 \\
\hline Use communication tool like "Ownership" & 10 & 9 & 125 & 98 & 77 & 96 & 48 & 100 \\
\hline Use communication tool like "l"' statements & 11 & 10 & 123 & 95 & 75 & 94 & 48 & 96 \\
\hline Ask open-ended questions & 189 & 94 & 116 & 92 & 72 & 94 & 44 & 90 \\
\hline Ask indirect questions & 58 & 36 & 13 & 43 & 7 & 44 & 6 & 43 \\
\hline Ask non-suggestive questions & 78 & 45 & 107 & 86 & 66 & 85 & 41 & 87 \\
\hline Identify concerns/worries and fears of the client & 62 & 32 & 92 & 69 & 52 & 65 & 40 & 75 \\
\hline Examine the client & 159 & 80 & 84 & 63 & 54 & 68 & 30 & 57 \\
\hline Seek permission from the client before conducting any examination of the client or accompanying infant & 8 & 5 & 0 & 0 & 0 & 0 & 0 & 0 \\
\hline Inform the client about the reasons for carrying out the examination & 20 & 13 & 6 & 7 & 5 & 9 & 1 & 3 \\
\hline Inform the client of the results of the examination & 53 & 34 & 46 & 55 & 32 & 59 & 14 & 48 \\
\hline Assess the most pressing $\mathrm{RH} /$ health need of the client. & 152 & 79 & 123 & 95 & 77 & 97 & 46 & 90 \\
\hline Assess other RH needs of the client (maternal health/child health and family planning) & 39 & 22 & 48 & 37 & 32 & 41 & 16 & 31 \\
\hline Assess the reproductive health intentions of the client's maternal care/ pregnancy, childcare and family planning. & 26 & 76 & 37 & 88 & 25 & 89 & 12 & 86 \\
\hline Assess the source of decision-making (power) in home & 19 & 14 & 7 & 16 & 3 & 13 & 4 & 19 \\
\hline Explore pre-existing knowledge about issue/problem & 24 & 13 & 50 & 38 & 28 & 35 & 22 & 43 \\
\hline Determine-underline attitudes and health beliefs but do not be judgmental & 21 & 11 & 114 & 86 & 75 & 94 & 39 & 74 \\
\hline
\end{tabular}




\begin{tabular}{|c|c|c|c|c|c|c|c|c|}
\hline & \multicolumn{2}{|c|}{ Baseline } & \multicolumn{2}{|c|}{ Endline } & \multicolumn{2}{|c|}{ Untrained } & \multicolumn{2}{|c|}{ Trained } \\
\hline & $\mathrm{N}$ & $\%$ & $\mathrm{~N}$ & $\%$ & $\mathrm{~N}$ & $\%$ & $\mathrm{~N}$ & $\%$ \\
\hline \multicolumn{9}{|l|}{ Help } \\
\hline Try to negotiate a solution to the problem with the client & 19 & 10 & 9 & 7 & 3 & 4 & 6 & 12 \\
\hline Mention range of options from which the client could choose a solution & 10 & 5 & 8 & 6 & 3 & 4 & 5 & 9 \\
\hline Provide sufficient information to empower the client to be able to address his or her needs & 48 & 24 & 53 & 40 & 28 & 35 & 25 & 47 \\
\hline Maintain the atmosphere of equality & 175 & 89 & 124 & 93 & 72 & 90 & 52 & 98 \\
\hline Provide ample time to listen to the needs of client & 94 & 48 & 89 & 67 & 52 & 65 & 37 & 70 \\
\hline Encourage the client to speak & 19 & 10 & 9 & 7 & 5 & 6 & 4 & 8 \\
\hline Avoid giving unsolicited advice & 100 & 92 & 130 & 98 & 79 & 99 & 51 & 96 \\
\hline Maintain eye to eye contact & 163 & 83 & 130 & 98 & 78 & 98 & 52 & 98 \\
\hline Use an appropriate tone and body language & 176 & 88 & 131 & 98 & 79 & 99 & 52 & 98 \\
\hline Avoid aggressive and passive behaviour & 192 & 96 & 132 & 99 & 79 & 99 & 53 & 100 \\
\hline Adopt assertive behaviour & 169 & 85 & 119 & 90 & 71 & 89 & 48 & 92 \\
\hline Provide a wide range of options & 14 & 7 & 17 & 13 & 9 & 12 & 8 & 15 \\
\hline Provide method/medicine & 175 & 88 & 112 & 85 & 64 & 81 & 48 & 91 \\
\hline Give sufficient information to the client about the negotiated solution & 36 & 19 & 28 & 21 & 14 & 18 & 14 & 26 \\
\hline Refer the client & 12 & 6 & 7 & 5 & 2 & 3 & 5 & 10 \\
\hline Provide referral information about where to go & 12 & 92 & 5 & 71 & 2 & 100 & 3 & 60 \\
\hline Provide referral information about when to go & 5 & 38 & 0 & 0 & 0 & 0 & 0 & 0 \\
\hline Provide referral information about distance involved & 2 & 15 & 2 & 29 & 0 & 0 & 2 & 40 \\
\hline Provide referral information about convenient mode of transport & 0 & 0 & 0 & 0 & 0 & 0 & 0 & 0 \\
\hline Provide referral information about estimated cost & 1 & 8 & 1 & 14 & 1 & 50 & 0 & 0 \\
\hline Provide referral information about total time it would take & 0 & 0 & 0 & 0 & 0 & 0 & 0 & 0 \\
\hline Provide referral information about directions on how to reach the facility & 2 & 15 & 0 & 0 & 0 & 0 & 0 & 0 \\
\hline Try to discuss the mutually agreed solution with other members of the family of the client & 23 & 19 & 26 & 57 & 16 & 59 & 10 & 53 \\
\hline \multicolumn{9}{|l|}{ Reassurance } \\
\hline Ask the client to repeat his/her instructions & 11 & 5 & 0 & 0 & 0 & 0 & 0 & 0 \\
\hline Allow the client to ask questions & 10 & 5 & 1 & 1 & 0 & 0 & 1 & 2 \\
\hline Reassure client and allay fears & 40 & 20 & 52 & 39 & 28 & 35 & 24 & 45 \\
\hline Provide support and encouragement & 33 & 16 & 48 & 36 & 23 & 29 & 25 & 47 \\
\hline Reassure the client that in case of need he/she can contact him/her at any time & 21 & 10 & 6 & 5 & 5 & 6 & 1 & 2 \\
\hline Reassure the client if condition doesn't improve, other option can be discussed & 9 & 5 & 4 & 3 & 3 & 4 & 1 & 2 \\
\hline Tell the client when to return for follow-up & 67 & 36 & 69 & 52 & 43 & 54 & 26 & 49 \\
\hline
\end{tabular}

